\title{
MOF-Based Adsorbents for Atmospheric Emission Control: A Review
}

\author{
Nicola Gargiulo 1,2,*(D), Antonio Peluso 1,3- and Domenico Caputo 1,3,4 \\ 1 ACLabs-Laboratori di Chimica Applicata, Dipartimento di Ingegneria Chimica, dei Materiali e della \\ Produzione Industriale, Università di Napoli Federico II, P.le V. Tecchio 80, 80125 Napoli, Italy; \\ apeluso@gmail.com (A.P.); domenico.caputo@unina.it (D.C.) \\ 2 Centro Regionale di Competenza (CRdC) Tecnologie Scarl, Via Nuova Agnano 11, 80125 Napoli, Italy \\ 3 CeSMA-Centro di Servizi Metrologici e Tecnologici Avanzati, Università di Napoli Federico II, Corso N. \\ Protopisani, 80146 Napoli, Italy \\ 4 INSTM-Consorzio Interuniversitario Nazionale per la Scienza e Tecnologia dei Materiali, Via G. Giusti, 9, \\ 50121 Firenze, Italy \\ * Correspondence: ngargiul@unina.it
}

Received: 16 April 2020; Accepted: 18 May 2020; Published: 21 May 2020

\begin{abstract}
This review focuses on the use of metal-organic frameworks (MOFs) for adsorbing gas species that are known to weaken the thermal self-regulation capacities of Earth's atmosphere. A large section is dedicated to the adsorption of carbon dioxide, while another section is dedicated to the adsorption of other different gas typologies, whose emissions, for various reasons, represent a "wound" for Earth's atmosphere. High emphasis is given to MOFs that have moved enough ahead in their development process to be currently considered as potentially usable in "real-world" (i.e., out-of-lab) adsorption processes. As a result, there is strong evidence of a wide gap between laboratory results and the industrial implementation of MOF-based adsorbents. Indeed, when a MOF that performs well in a specific process is commercially available in large quantities, economic observations still make designers tend toward more traditional adsorbents. Moreover, there are cases in which a specific MOF remarkably outperforms the currently employed adsorbents, but it is not industrially produced, thus strongly limiting its possibilities in large-scale use. To overcome such limitations, it is hoped that the chemical industry will be able to provide more and more mass-produced MOFs at increasingly competitive costs in the future.
\end{abstract}

Keywords: metal-organic frameworks; adsorption; greenhouse gases; atmospheric environment; climate change

\section{Introduction}

Since its first historical traces, mankind has never had to face global challenges such as those happening in the contemporary age. Among them, climate change is the challenge nowadays considered to be the most threatening for the survival of the whole human race [1]. Climate change is mainly dependent on the energy transport phenomena occurring between Earth and outer space. In turn, such energy transport phenomena are strongly related to the physicochemical status of Earth's atmosphere. After the Industrial Revolution took place from the second half of the 18th century to the first half of the 19th century, anthropic activities started to dramatically influence the "health" of the Earth's atmosphere. Therefore, the energy balance of our planet is being modified in such a way that its average temperature is abnormally increasing (global warming). This temperature increase is already causing anomalous climatic events, which are unprecedented in human history and recall prehistorical periods of planetary crisis such as Late Quaternary extinctions [2]. In order to try reverting 
global warming, immediate action must be taken to minimize anthropic emissions that modify the chemical composition of Earth's atmosphere. Among the unit operations of the process industry, adsorption has turned out to be the most efficient for separating gas mixtures in fractions or in pure components [3]. In other words, adsorption represents the cleanest way of capturing pollutants from end-of-process gas streams that are discharged into the atmosphere. When designing an adsorption system, one of the crucial choices concerns the type of adsorbent material that will be used in the packed beds. The materials mostly contemplated for adsorption processes are nanoporous materials [4], in particular, microporous materials (with pore sizes below $2 \mathrm{~nm}$ ) and mesoporous materials (with pore sizes between 2 and $50 \mathrm{~nm}$ ). During the last 15 years, microporous metal-organic frameworks (MOFs) have shown great potential for improving the performances of different industrially relevant, adsorption-based applications [5]. This review will focus on the use of MOFs for adsorbing gas species, which are known to weaken the thermal self-regulation capacities of Earth's atmosphere. Obviously, a large section will be dedicated to the adsorption of carbon dioxide, whose emissions are the main cause of the so-called greenhouse effect, while another section will be dedicated to the adsorption of other different gas typologies (e.g., fluorinated gases, volatile organic compounds, etc.) whose emissions, for various reasons, represent a "wound" for Earth's atmosphere. Nevertheless, the critical approach to the following literature survey was based on the search for the three main functionalities that an ideal adsorbent should always feature:

1. High adsorption capacity toward the target adsorptive (i.e., the value of the adsorbed amount of substance observed in saturation conditions);

2. High selectivity toward the target adsorptive (i.e., the ability of the adsorbent to preferably adsorb one adsorptive when mixed with others); and

3. High regeneration capacity (i.e., the possibility of removing the adsorbate by means of simple and inexpensive methods, in order to use the same adsorbent for repeated adsorption cycles).

Moreover, high emphasis will be given to studies about MOFs that have moved ahead enough in their development process to be currently considered as potentially usable in "real-world" (i.e., out-of-lab) adsorption processes. The crystal structures of some of these MOFs, whose performances as adsorbents will be detailed in the next sections, are shown in Figure 1. 


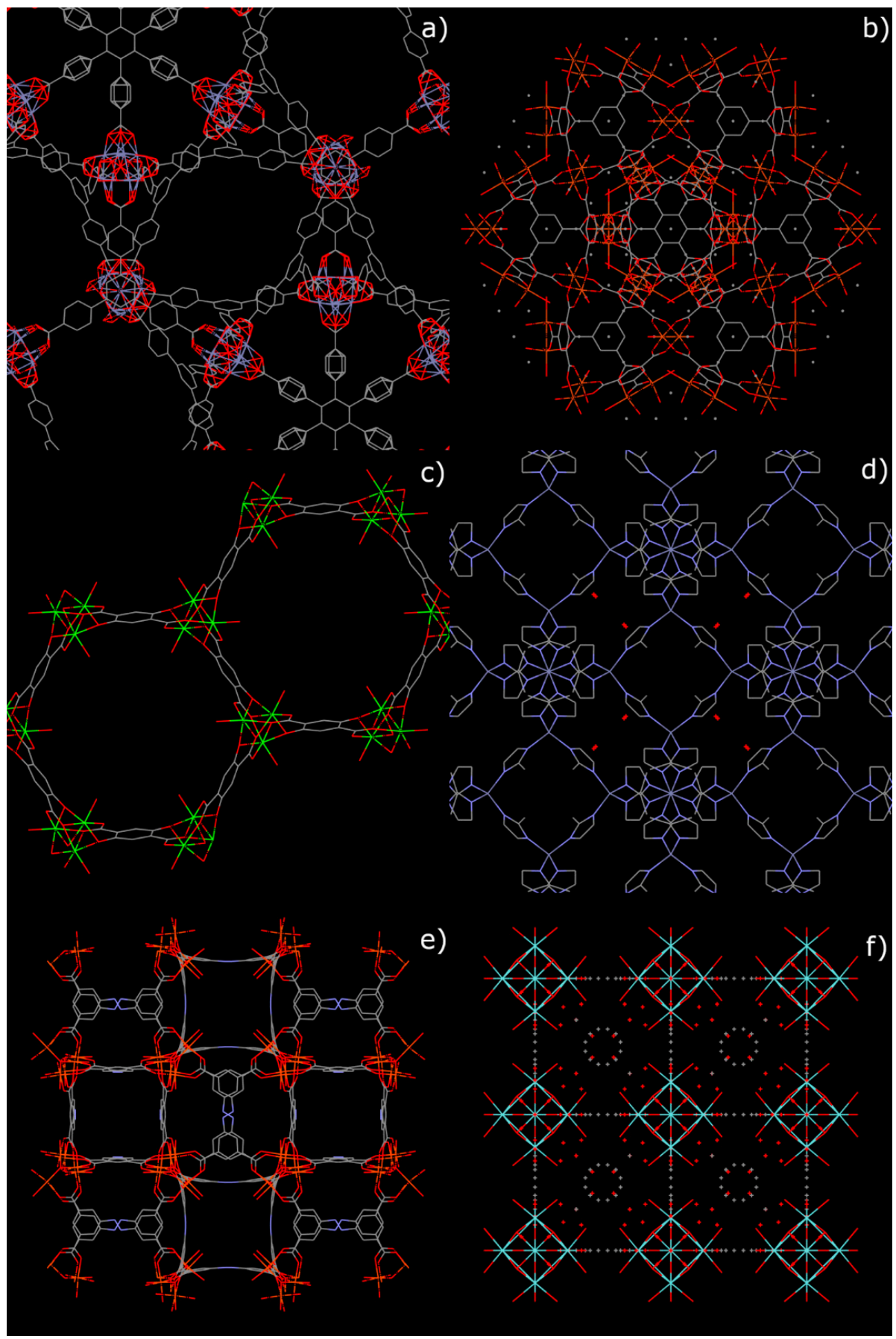

Figure 1. Crystal structures of some mass-produced metal-organic frameworks (MOFs): (a) MOF-177; (b) Cu-BTC; (c) Mg-MOF-74; (d) ZIF-8; (e) PCN-250 (Fes); (f) UiO-66.

\section{2. $\mathrm{CO}_{2}$ Adsorption on Metal-Organic Frameworks (MOFs)}

Starting from the advent of the Industrial Revolution, anthropic activities have caused an increase in the carbon dioxide atmospheric concentration of more than $50 \%$ (i.e., from about $260 \mathrm{ppm}$ of pre-industrial era [6] to the current $400 \mathrm{ppm}$ (and more) [7]). Such anomalous change in the composition of Earth's atmosphere is significantly reducing the fraction of absorbed solar radiant energy that the planet gives back to outer space. This phenomenon, known as the greenhouse effect [8], is the main cause of the abnormal planetary temperature rise registered during the last two centuries. Anthropic $\mathrm{CO}_{2}$ emissions mainly come from three sources: 
1. Transportation, through the combustion of fossil fuels;

2. Electricity production, (again) through the combustion of fossil fuels; and

3. Industry, through reforming fossil fuels, gaseous byproducts of industrial steelmaking and the cement industry, etc.

With particular regard to the last two scenarios, the implementation of adsorption columns downstream of electricity production and industrial plants can provide a drastic reduction in $\mathrm{CO}_{2}$ emissions [9]. Up to the end of the last century, zeolites were considered as the best option among nanoporous adsorbents for $\mathrm{CO}_{2}$ capture, and they are still considered the benchmark in terms of a benefit-cost ratio [10] because zeolites can also be synthesized starting from several waste materials [11]. In the last two decades, a lot of effort has been focused on studying the $\mathrm{CO}_{2}$ adsorption properties of functionalized mesoporous silicates [12-16]. Gradually, in the last 15 years, there has been an exponential development of studies about the $\mathrm{CO}_{2}$ adsorption properties of MOFs. Readers who are interested only in this specific topic are invited to also read a recent review by Ghanbari et al. [17]. With respect to the latter paper, rather than focusing on the correlation between MOF structures and $\mathrm{CO}_{2}$ adsorption performances, this section of the present review will give emphasis to the actual suitability of MOFs to be used in industrial $\mathrm{CO}_{2}$ adsorption processes. In particular, potential applications in packed bed adsorption columns will be taken into account, whereas membrane-based separation needs specific treatises [18]. An overview of the recent (limited to the last decade) literature about this subject is reported in Table 1. For the purpose of analyzing these data, Table 2 reports the $\mathrm{CO}_{2}$ removal performances of the state-of-the-art currently used technologies like zeolite- and activated carbon-based adsorbents and amine scrubs.

Table 1. Metal-organic frameworks (MOFs) potentially suitable for $\mathrm{CO}_{2}$ adsorption.

\begin{tabular}{|c|c|c|}
\hline MOF Type & $\begin{array}{c}\mathrm{CO}_{2} \text { Adsorption Capacity }{ }^{1}, \mathrm{~mol} / \mathrm{kg} \\
(\text { Reported Working Conditions, } T \text { and } p)^{2}\end{array}$ & Reference \\
\hline \multirow{3}{*}{ MOF-177 } & $9.02(298 \mathrm{~K}, 1400 \mathrm{kPa})$ & [19] \\
\hline & $1.00(298 \mathrm{~K}, 100 \mathrm{kPa})$ & [20] \\
\hline & $0.93(293 \mathrm{~K}, 100 \mathrm{kPa})$ & {$[21]$} \\
\hline Ionic liquid-Functionalized MOF-177 & $1.14(303 \mathrm{~K}, 100 \mathrm{kPa})$ & [22] \\
\hline \multirow{4}{*}{$\mathrm{Cu}-\mathrm{BTC}$} & $7.00(283 \mathrm{~K}, 100 \mathrm{kPa})$ & [23] \\
\hline & $14.00(303 \mathrm{~K}, 4000 \mathrm{kPa})$ & [24] \\
\hline & $8.07(303 \mathrm{~K}, 1000 \mathrm{kPa})$ & [25] \\
\hline & $11.70(297 \mathrm{~K}, 1500 \mathrm{kPa})$ & [26] \\
\hline Ionic liquid-Functionalized Cu-BTC & $1.70(303 \mathrm{~K}, 15 \mathrm{kPa})$ & [27] \\
\hline Li-Doped Cu-BTC & $4.85(298 \mathrm{~K}, 100 \mathrm{kPa})$ & [28] \\
\hline \multirow{4}{*}{ Mg-MOF-74 } & $8.61(298 \mathrm{~K}, 100 \mathrm{kPa})$ & [29] \\
\hline & $9.02(293 \mathrm{~K}, 100 \mathrm{kPa})$ & [21] \\
\hline & $15.00(313 \mathrm{~K}, 3500 \mathrm{kPa})$ & [30] \\
\hline & $14.80(303 \mathrm{~K}, 3000 \mathrm{kPa})$ & [31] \\
\hline Mg-MOF-74-Polystyrene composite & $4.98(298 \mathrm{~K}, 100 \mathrm{kPa})$ & [32] \\
\hline \multirow{2}{*}{$\begin{array}{l}\text { Tetraethylenepentamine-Functionalized } \\
\text { Mg-MOF-74 }\end{array}$} & $\begin{array}{c}6.06 \text { (breakthrough, } \mathrm{CO}_{2} / \mathrm{N}_{2} \text { mixture, }\left[\mathrm{CO}_{2}\right] \\
=15 \mathrm{~mol} \%, 333 \mathrm{~K} \text { ) }\end{array}$ & [33] \\
\hline & $6.11(298 \mathrm{~K}, 100 \mathrm{kPa})$ & [34] \\
\hline
\end{tabular}


Table 1. Cont.

\begin{tabular}{|c|c|c|}
\hline MOF Type & $\begin{array}{c}\mathrm{CO}_{2} \text { Adsorption Capacity }{ }^{1}, \mathrm{~mol} / \mathrm{kg} \\
\text { (Reported Working Conditions, } T \text { and } p)^{2}\end{array}$ & Reference \\
\hline Ethylenediamine-Functionalized Mg-MOF-74 & $5.42(298 \mathrm{~K}, 100 \mathrm{kPa})$ & [35] \\
\hline \multirow{2}{*}{ ZIF-8 } & $8.60(303 \mathrm{~K}, 4000 \mathrm{kPa})$ & [36] \\
\hline & $9.10(303 \mathrm{~K}, 4500 \mathrm{kPa})$ & [37] \\
\hline Ammonia-Functionalized ZIF-8 & $7.50(298 \mathrm{~K}, 3000 \mathrm{kPa})$ & [38] \\
\hline Ethylenediamine-Functionalized ZIF-8 & $9.85(298 \mathrm{~K}, 2500 \mathrm{kPa})$ & [39] \\
\hline Tetraethylenepentamine-Functionalized ZIF-8 & $\begin{array}{l}\text { 2.18-3.19, depending on the amine content } \\
(318 \mathrm{~K}, 500 \mathrm{kPa})\end{array}$ & [40] \\
\hline 3-amino-1,2,4-triazole-Functionalized ZIF-8 & $2.51(308 \mathrm{~K}, 200 \mathrm{kPa})$ & [41] \\
\hline 2-nitrobenzimidazole-Functionalized ZIF-8 & $3.39(273 \mathrm{~K}, 120 \mathrm{kPa})$ & [42] \\
\hline Thermally annealed ZIF-8 & $3.00(298 \mathrm{~K}, 250 \mathrm{kPa})$ & [43] \\
\hline Li-Doped polyoxometalate-ZIF-8 composite & $16.00(298 \mathrm{~K}, 1000 \mathrm{kPa})$ & [44] \\
\hline Ionic liquid-Functionalized ZIF-8 & $0.83(303 \mathrm{~K}, 20 \mathrm{kPa})$ & [45] \\
\hline \multirow[t]{2}{*}{ PCN-250 $\left(\mathrm{Fe}_{3}\right)$} & $\begin{array}{c}5.24 \text { (breakthrough, } \mathrm{CO}_{2} / \mathrm{N}_{2} \text { mixture, }\left[\mathrm{CO}_{2}\right] \\
=15 \mathrm{vol} \%, 303 \mathrm{~K})\end{array}$ & [46] \\
\hline & $3.02(298 \mathrm{~K}, 100 \mathrm{kPa})$ & [47] \\
\hline \multirow{4}{*}{$\mathrm{UiO}-66$} & $7.65(303 \mathrm{~K}, 6000 \mathrm{kPa})$ & [48] \\
\hline & $7.29(298 \mathrm{~K}, 3000 \mathrm{kPa})$ & [49] \\
\hline & $1.48(303 \mathrm{~K}, 100 \mathrm{kPa})$ & [50] \\
\hline & $4.34(298 \mathrm{~K}, 2000 \mathrm{kPa})$ & [51] \\
\hline Ti-Exchanged UiO-66 & $4.37(273 \mathrm{~K}, 120 \mathrm{kPa})$ & [52] \\
\hline Adipic acid-Functionalized UiO-66 & $3.76(273 \mathrm{~K}, 100 \mathrm{kPa})$ & [53] \\
\hline Ethanolamine-Functionalized UiO-66 & $1.70(298 \mathrm{~K}, 100 \mathrm{kPa})$ & [54] \\
\hline Polyethylenimine_-Functionalized UiO-66 & $3.32(298 \mathrm{~K}, 100 \mathrm{kPa})$ & [55] \\
\hline Tetraethylenepentamine-Functionalized UiO-66 & $\begin{array}{c}3.70 \text { (breakthrough, } \mathrm{CO}_{2} / \mathrm{He} \text { mixture, }\left[\mathrm{CO}_{2}\right] \\
\quad=10 \mathrm{vol} \%, 348 \mathrm{~K}, 100 \mathrm{kPa} \text { ) }\end{array}$ & [56] \\
\hline Li-Doped UiO-66 & $2.80(298 \mathrm{~K}, 100 \mathrm{kPa})$ & [57] \\
\hline
\end{tabular}

${ }^{1}$ Where not explicitly reported in the cited papers, $\mathrm{CO}_{2}$ adsorption capacity values were extracted from plots using reverse engineering software. ${ }^{2}$ Where not explicitly reported, working conditions imply the collection of pure $\mathrm{CO}_{2}$ adsorption isotherms.

Table 2. $\mathrm{CO}_{2}$ removal performances of the state-of-the-art currently used technologies.

\begin{tabular}{ccc}
\hline Type of $\mathrm{CO}_{\mathbf{2}}$ Remover & $\begin{array}{c}\mathrm{CO}_{\mathbf{2}} \text { Uptake Capacity }{ }^{\mathbf{1}}, \mathbf{m o l} / \mathbf{k g} \text { (Reported } \\
\text { Working Conditions, } \mathbf{T} \text { and } \boldsymbol{p})\end{array}$ & Reference \\
\hline 13X zeolite adsorbent & $4.80(283 \mathrm{~K}, 100 \mathrm{kPa})$ & {$[23]$} \\
\hline Maxsorb III activated carbon adsorbent & $36.98(283 \mathrm{~K}, 4250 \mathrm{kPa})$ & {$[58]$} \\
\hline $5 \mathrm{~N}$ aqueous solution of monoethanolamine scrub & $19.32(298 \mathrm{~K}, 10,000 \mathrm{kPa})$ & {$[59]$} \\
\hline $\begin{array}{l}{ }^{1} \text { Where not explicitly reported in the cited papers, } \mathrm{CO}_{2} \text { uptake capacity values were extracted from plots using } \\
\text { reverse engineering software. }\end{array}$
\end{tabular}

In one of the first systematic works about the use of MOFs for adsorbing greenhouse gases [19], Saha et al. investigated $\mathrm{CO}_{2}$ adsorption on MOF-5 and MOF-177 with respect to a traditional adsorbent such as the $5 \mathrm{~A}$ zeolite. It is important to highlight that these two MOFs are among the ones that have been the most studied, and can be considered the nearest to actual implementation in real-world processes. In particular, MOF-177 is already produced on an industrial scale and commercialized under the brand Basolite ${ }^{\circledR} \mathrm{Z} 377$ [60]. The $\mathrm{CO}_{2}$ adsorption capacity reported in [19] for MOF-177 by far exceeds that of the $5 \mathrm{~A}$ zeolite when considering high pressures, but the $5 \mathrm{~A}$ zeolite is capable of exploiting the most part of its total adsorption capacity at sub-atmospheric pressure (i.e., it has a higher 
affinity toward $\mathrm{CO}_{2}$ than MOF-177). As a consequence, MOF-177 should outperform the traditional adsorbent in pressure swing adsorption (PSA) [61], rather than in vacuum swing adsorption (VSA) [62]. MOF-177 also showed a fair $\mathrm{CO}_{2} / \mathrm{N}_{2}$ selectivity (which should make it suitable for $\mathrm{CO}_{2}$ capture from flue gas streams) and provided hints of a good regeneration capacity (i.e., the complete reversibility of $\mathrm{CO}_{2}$ adsorption has been checked up to atmospheric pressure).

More recently [20], Ullah et al. investigated the potential use of MOF-177 for $\mathrm{CO}_{2} / \mathrm{CH}_{4}$ separation, which is a key step in natural gas upgrading processes. $\mathrm{CO}_{2} / \mathrm{CH}_{4}$ thermodynamical selectivity was calculated starting from pure component adsorption isotherms by means of the ideal adsorbed solution theory (IAST), finding a value acceptable for envisaging a plant-scale application.

Still recently [22], Mohamedali et al. tried to increase the affinity of MOF-177 toward $\mathrm{CO}_{2}$ by means of functionalization with ionic liquids. Unfortunately, the results of such a modification procedure cannot be considered quite as satisfactory. Indeed, as explained in more detail below, the post-synthesis adjustment of the $\mathrm{CO}_{2}$ adsorption behavior of a MOF is quite ineffective if, as in the case of MOF-177 [63], the adsorbent surface is a priori lacking in exposed coordinatively unsaturated sites.

Another MOF that can be considered mature enough for real-world applications is the copper benzene-1,3,5-tricarboxylate known as MOF-199, HKUST-1, or Cu-BTC. Indeed, this MOF has also been the main subject of hundreds of research papers and is currently produced on an industrial scale, commercialized under the brand Basolite ${ }^{\circledR} \mathrm{C} 300$ [60]. In about a decade, $\mathrm{CO}_{2}$ adsorption on Cu-BTC has been investigated deeply down to the molecular level, initially through speculative considerations induced by direct adsorption measurements [23], and then through extremely fine-tuned experimental setups [64]. From the application point of view, Hamon et al. [24] managed to approach the structural limits of the $\mathrm{CO}_{2}$ adsorption capacity of $\mathrm{Cu}$-BTC, obtaining adsorbed quantities about twice higher than those obtained at atmospheric pressure and less-than-ambient temperature [23]. Moreover, in [24], breakthrough experiments allowed the authors to notice a good $\mathrm{CO}_{2} / \mathrm{CH}_{4}$ selectivity, which would make $\mathrm{Cu}$-BTC suitable for natural gas upgrading processes. The same breakthrough experiments allowed for the observation of the remarkable regeneration capacities of the MOF adsorbent, with a measured $\mathrm{CO}_{2}$ delta loading of $7.37 \mathrm{~mol} / \mathrm{kg}$ between the adsorption step at $1000 \mathrm{kPa}$ and the desorption step at $100 \mathrm{kPa}$ for a $70-15-15 \mathrm{CO}_{2}-\mathrm{CH}_{4}-\mathrm{CO}$ ternary feed.

Some years later [25], Ye et al. focused their attention on the potential use of $\mathrm{Cu}-\mathrm{BTC}$ in $\mathrm{CO}_{2}$ capture from flue gas. Apart from the equilibrium characterization of the adsorbent, they performed breakthrough experiments that highlighted a good selectivity for $\mathrm{CO}_{2}$ over $\mathrm{N}_{2}$. Moreover, repeated adsorption/desorption cycles allowed for the regeneration capabilities of $\mathrm{Cu}$-BTC to be checked and to identify the temperature swing adsorption (TSA) as a preferable operating mode with respect to VSA.

Very recently [26], Kloutse et al. published a work that attracted attention not only for the peculiar experimental methods used for performing adsorption runs, but also for having highlighted the good $\mathrm{CO}_{2} / \mathrm{H}_{2}$ selectivity of $\mathrm{Cu}$-BTC. Indeed, the separation of this specific couple of gases is a crucial step downstream of steam reforming processes and is usually carried out by absorption in aqueous solvents such as moderately concentrated amine solutions. Substituting chemical absorbers with adsorption columns for this task (especially if operating in PSA or VSA modes) could provide clear advantages in terms of energy efficiency (i.e., no heat needed during the regeneration of the columns) and plant maintenance costs (i.e., no plant component attacked by chemically aggressive liquids).

Like MOF-177, Cu-BTC has also been the object of functionalization trials, in order to fine-tune its $\mathrm{CO}_{2}$ adsorption behavior. As an example, Da Silva et al. functionalized $\mathrm{Cu}$-BTC with ionic liquids and tested the resulting materials for $\mathrm{CO}_{2}$ adsorption, actually finding no significant benefits in the modified adsorbents with respect to pristine Cu-BTC [65]. A different conclusion was obtained by Mohamedali et al. [27], who impregnated Cu-BTC with 1-butyl-3-methylimidazolium acetate ([bmim][Ac]) and doubled the $\mathrm{CO}_{2}$ adsorption capacity of the pristine MOF at $15 \mathrm{kPa}$, which is a typical value for $\mathrm{CO}_{2}$ partial pressure in flue gas during the adsorption step of VSA and TSA processes. Moreover, [bmim][Ac]-functionalized $\mathrm{Cu}$-BTC proved to be fully regenerable after several $\mathrm{CO}_{2}$ adsorption/desorption cycles. 
A distinct approach was adopted by Zhou et al., who impregnated different Cu-BTC samples with lithium nitrate and then heat-treated them under vacuum, nearly doubling the $\mathrm{CO}_{2}$ adsorption capacity with respect to the pristine $\mathrm{MOF}$ [28]. Moreover, the $\mathrm{CO}_{2}$ equilibrium adsorption curve of Li-doped Cu-BTC resulted in being completely overlapped with the desorption one, thus indicating complete reversibility of the adsorption process (i.e., the possibility of fully regenerating the adsorbent in cyclic operations).

Trying to take one more step toward a real-world use of $\mathrm{Cu}-\mathrm{BTC}$ in $\mathrm{CO}_{2}$ adsorption processes, it must be noted that both flue and natural gas usually contain water vapor, and that the interaction between Cu-BTC and water vapor can be quite problematic. Indeed, depending on the synthesis route, water can be present inside the Cu-BTC structure in the form of guest molecules that can be removed by activation, thus exposing coordinatively unsaturated sites (CUSs) [66]. If rehydration occurs, water molecules can react with CUSs, causing ligand displacement and/or hydrolysis [67], which eventually leads to structural collapse. Such an event has been confirmed for Cu-BTC, under specific conditions by Al-Janabi et al. [68], who investigated the hydration process of this MOF using dynamic water vapor adsorption under flue gas emitting conditions. The same authors also found a range of values for state variables (temperature, relative humidity, and vapor partial pressure) suitable for preserving the structural integrity of $\mathrm{Cu}-\mathrm{BTC}$ in the presence of moisture.

Another MOF that has been deeply studied in terms of $\mathrm{CO}_{2}$ adsorption is the magnesium variant of MOF-74, also known as Mg-CPO-27 and commercialized under the brand Porolite ${ }^{\circledR}$ M7 [60]. As an example, Bao et al. measured $\mathrm{CO}_{2}$ adsorption/desorption isotherms on Mg-MOF-74 up to atmospheric pressure, finding a remarkable adsorption capacity at ambient temperature [29]. They also extracted the $\mathrm{CO}_{2} / \mathrm{CH}_{4}$ kinetic selectivity from the direct reading of gas pressure and adsorption volume changes with time during the survey of the isotherm points. Such obtained results can thus be hardly compared with those obtainable by means of breakthrough experiments. With regard to the regeneration capacity, the $\mathrm{CO}_{2}$ adsorption and desorption branches of the isotherms basically overlapped with each other, suggesting the occurrence of a reversible process.

Among the MOFs most studied for $\mathrm{CO}_{2}$ adsorption, $\mathrm{Cu}-\mathrm{BTC}$ and Mg-MOF-74 also stood out for their common structural feature (i.e., the presence of CUSs). CUSs are supposed to act as preferential $\mathrm{CO}_{2}$ adsorption sites due to their capability of interacting with molecular quadrupoles [23]. Such hypothesis has been strengthened first by theoretical predictions of first-principles (DFT) studies [69], and then confirmed by specific experimental investigations (e.g., 2D correlation spectroscopy [64]). As an example of how CUSs can influence $\mathrm{CO}_{2}$ adsorption behavior in MOFs, Mason et al. compared $\mathrm{CO}_{2}$ adsorption isotherms at ambient temperature up to atmospheric pressure on both MOF-177 and Mg-MOF-74 [21]. In such conditions, the latter MOF adsorbed much more $\mathrm{CO}_{2}$ than MOF-177, mainly because of its CUSs, which were completely absent in MOF-177 [63]. CUSs were also responsible for the high $\mathrm{CO}_{2}$ over $\mathrm{N}_{2}$ thermodynamical selectivity in Mg-MOF-74, which makes such an adsorbent suitable for $\mathrm{CO}_{2}$ capture from flue gas streams by means of TSA [21].

Shortly afterward [30], Herm et al. measured $\mathrm{CO}_{2}, \mathrm{CH}_{4}$, and $\mathrm{H}_{2}$ high pressure adsorption isotherms on Mg-MOF-74 and used IAST for calculating both binary (i.e., $\mathrm{CO}_{2} / \mathrm{CH}_{4}$ and $\mathrm{CO}_{2} / \mathrm{H}_{2}$ ) and ternary (i.e., $\left.\left(\mathrm{CO}_{2}+\mathrm{CH}_{4} / \mathrm{H}_{2}\right)\right)$ thermodynamic selectivity, the latter being particularly important due to the incomplete $\mathrm{CH}_{4} \rightarrow \mathrm{H}_{2}$ conversion that can occur in reforming processes and to the very high $\mathrm{H}_{2}$ purity required (e.g., for feeding fuel cells). In any case, Mg-MOF-74 performed better than a benchmark adsorbent such as $13 \mathrm{X}$ zeolite.

Still regarding comparisons with 13X zeolite, Remy et al. made pellets of Mg-MOF-74 to be used in dynamic breakthrough separation experiments with $\mathrm{CO}_{2} / \mathrm{CH}_{4}$ mixtures in a packed column, finding a higher $\mathrm{CO}_{2}$ adsorption capacity and separation efficiency for the MOF with respect to the benchmark zeolite [31]. Unfortunately, the performance of Mg-MOF-74 was found to severely deteriorate upon long-term exposure to relevant impurities in natural gas such as water vapor.

The latter conclusion was more recently confirmed by Qasem et al., who compared the $\mathrm{CO}_{2}$ adsorption separation performances from simulated humid flue gas (i.e., $\mathrm{CO}_{2} / \mathrm{N}_{2} /$ water vapor mixture) 
of Mg-MOF-74 and 13X zeolite [70]. In addition, the experiments reported in this work were carried out using a packed column setup, performing both simple breakthrough and cyclic tests and concluding that a dehydration process before $\mathrm{CO}_{2}$ adsorption is strongly recommended.

More details about the incidence of water vapor on the $\mathrm{CO}_{2}$ adsorption performances of Mg-MOF-74 was given by Mangano et al. [71], who used the zero length column (ZLC) technique for probing the stability of Mg-MOF-74 crystals in the presence of water and humid flue gas. The results evidenced that Mg-MOF-74 showed a very fast deactivation, with most of its $\mathrm{CO}_{2}$ adsorption capacity lost after a few adsorption/desorption cycles.

Since Mg-MOF-74 cannot be used in processes that envisage direct contact of the adsorbent with moisture, some post-synthesis treatments have been proposed in order to improve the water stability of this MOF. As an example, Moon et al. prepared a Mg-MOF-74-polystyrene composite by a simple solution-mixing method [32]. This material showed a lower $\mathrm{CO}_{2}$ adsorption capacity, but also a far higher water stability than those of pristine Mg-MOF-74.

Another type of modification, aimed at increasing the already remarkable $\mathrm{CO}_{2}$ adsorption capacity of Mg-MOF-74, consists of functionalizing it with amine compounds. In this regard, one of the first works was carried out by Cao et al. [33], who modified Mg-MOF-74 with tetraethylenepentamine (TEPA) and found that after functionalization, the $\mathrm{CO}_{2}$ adsorption capacity increased from 2.67 to $6.06 \mathrm{~mol} / \mathrm{kg}$. Moreover, this value was shown to suffer only a very slight decrease after repeated adsorption/desorption cycles. Similar results were obtained by Su et al. [34], who used a peculiar experimental setup for investigating $\mathrm{CO}_{2} / \mathrm{H}_{2} \mathrm{O}$ co-adsorption equilibrium on TEPA-functionalized Mg-MOF-74, finding that the incorporated amine seems to protect the adsorbent against water and to preserve its $\mathrm{CO}_{2}$ adsorption capacity.

Eventually, Bernini et al. modified Mg-MOF-74 with ethylenediamine (ED) [35]: similar to [bmim][Ac]—Functionalized Cu-BTC [27], this process decreased the $\mathrm{CO}_{2}$ adsorption capacity at atmospheric pressure, but increased it at lower pressures (i.e., increased the $\mathrm{CO}_{2}$ affinity of the adsorbent). Moreover, adsorption isotherms on ED-functionalized Mg-MOF-74 provided hints about a significantly higher $\mathrm{CO}_{2} / \mathrm{N}_{2}$ selectivity with respect to the pristine adsorbent. Unfortunately, the modified material was shown to undergo remarkable regeneration problems, and the $\mathrm{CO}_{2}$ adsorption capacity suffered from an important decrease in subsequent adsorption/desorption cycles.

Another MOF whose $\mathrm{CO}_{2}$ adsorption properties have been extensively studied belongs to the specific subcategory of zeolitic imidazolate frameworks (ZIFs) and is the zinc 2-methylimidazolate known as ZIF-8. Additionally, this MOF is currently produced on an industrial scale, commercialized, under the brand Basolite ${ }^{\circledR}$ Z1200 [60]. Quite interestingly, most of the studies about ZIF-8 and $\mathrm{CO}_{2}$ adsorption concern the use of this adsorbent as a dispersed phase in mixed matrix membranes (MMMs), with the performances of this MOF not outstanding at all when employed in particle form without any specific modification. Indeed, Pérez-Pellitero et al. measured $\mathrm{CO}_{2}, \mathrm{CH}_{4}$, and $\mathrm{N}_{2}$ high pressure adsorption isotherms on ZIF-8, finding a $\mathrm{CO}_{2}$ adsorption capacity far lower than several already reported in Table 1 [36]. McEwen et al. performed a similar investigation [72], focusing on the sub-atmospheric pressure range and finding that the $\mathrm{CO}_{2} / \mathrm{CH}_{4}$ and $\mathrm{CO}_{2} / \mathrm{N}_{2}$ selectivities of $\mathrm{ZIF}-8$ were significantly lower than those of a much cheaper benchmark adsorbent such as the 13X zeolite. These conclusions were further confirmed by Danaci et al., who investigated the potential suitability of ZIF-8 for $\mathrm{CO}_{2} / \mathrm{CH}_{4}$ separation under PSA conditions, finding that this MOF has insufficient selectivity for $\mathrm{CO}_{2}$ capture from natural gas [37].

The poor results provided by as-is ZIF- 8 have pushed investigations toward functionalization routes that could significantly enhance the $\mathrm{CO}_{2}$ adsorption performances of this adsorbent. As an example, Zhang et al. modified ZIF-8 samples by using ammonia impregnation, thus increasing the $\mathrm{CO}_{2}$ adsorption capacity by $45 \%$ and the $\mathrm{CO}_{2} / \mathrm{N}_{2}$ selectivity by $56 \%$ with respect to the parent MOF [38]. Moreover, almost complete regenerability of the adsorbent was verified by multiple $\mathrm{CO}_{2}$ adsorption-desorption cycles and checking the reversibility of the $\mathrm{CO}_{2}$ adsorption isotherm. These results were further improved by the same research group using ED functionalization [39]. In this 
way, the $\mathrm{CO}_{2}$ adsorption capacity and the $\mathrm{CO}_{2} / \mathrm{N}_{2}$ selectivity nearly doubled with respect to the parent MOF; in addition, in this case, the substantial regenerability of the adsorbent was verified by multiple $\mathrm{CO}_{2}$ adsorption-desorption cycles. Moreover, ED-functionalized ZIF-8 turned out to be more hydrophobic than its unfunctionalized counterpart. Such features could result in being especially useful if envisaging $\mathrm{CO}_{2}$ separation from flue gas streams that are not pretreated for moisture removal.

Still concerning amine functionalization, Martínez et al. modified ZIF-8 samples by wetness impregnation with TEPA, more than doubling the $\mathrm{CO}_{2}$ adsorption capacity of the parent MOF [40]. Additionally, $\mathrm{CO}_{2}$ adsorption on TEPA-functionalized ZIF-8 showed a significant enhancement under post-combustion conditions using a humid simulated flue gas stream. As is well known, water has a positive influence on the chemical reactions involved in $\mathrm{CO}_{2}$ adsorption onto amino groups [73]. Eventually, TEPA-functionalized ZIF-8 samples kept their $\mathrm{CO}_{2}$ adsorption capacity for several adsorption-desorption cycles.

More recently, Cho et al. performed the amino-functionalization of ZIF-8 through a novel route, consisting of an isomorphically substituting part of the MOF ligand with 3-amino-1,2,4-triazole (Atz) [41]. The $\mathrm{CO}_{2}$ adsorption capacity of the so-obtained material turned out to be almost 2.5-fold higher than that of the parent MOF. Moreover, both $\mathrm{CO}_{2} / \mathrm{N}_{2}$ and $\mathrm{CO}_{2} / \mathrm{CH}_{4}$ selectivity substantially increased. Unfortunately, no information was provided on the adsorbent regeneration and the possible interaction with water vapor.

Similar to the latter work, Tsai et al. [42] managed to exchange 2/3 of the total 2-methylimidazolate units in ZIF-8 structure with as much 2-nitrobenzimidazolate units. As a result, the $\mathrm{CO}_{2}$ adsorption capacity and affinity of the so-obtained adsorbent noticeably increased with respect to the parent MOF. Disappointingly, this material was not tested for selectivity performance in any kind of separation nor for the possibility of regenerating the adsorbent after a single $\mathrm{CO}_{2}$ adsorption run.

A particular mention can also be given to Gadipelli et al. [43], who adopted an original thermal annealing process for modifying the $\mathrm{CO}_{2}$ adsorption properties of ZIF-8. With respect to the parent $\mathrm{MOF}$, the annealed material showed a remarkably higher $\mathrm{CO}_{2}$ adsorption capacity and highly enhanced $\mathrm{CO}_{2} / \mathrm{N}_{2}$ selectivity as well as a stable $\mathrm{CO}_{2}$ uptake after more than 20 adsorption/desorption cycles.

Like Cu-BTC [28], ZIF-8 has also been the object of Li doping procedures in order to increase its $\mathrm{CO}_{2}$ adsorption performances. In the latter case [44], a polyoxometalate (POM)/MOF nanocomposite was first prepared. The presence of POM clusters inside ZIF-8 pores allowed for a significant amount of $\mathrm{Li}^{+}$ions to be loaded inside the adsorbent structure, thus noticeably increasing its $\mathrm{CO}_{2}$ adsorption capacity (especially at atmospheric pressure). Moreover, $\mathrm{CO}_{2}$ adsorption isotherms turned out to be totally reversible, thus suggesting the possibility of fully regenerating the adsorbent in cyclic operations. Unfortunately, no information was provided about selectivity performance in any kind of separation.

Eventually, as in the case of MOF-177 and Cu-BTC, there are some examples of the functionalization of ZIF-8 with ionic liquids in order to enhance its $\mathrm{CO}_{2}$ adsorption performances. In 2018, Mohamedali et al. impregnated ZIF-8 with [bmim][Ac] [45] and multiplied by seven the $\mathrm{CO}_{2}$ adsorption capacity of the pristine MOF at $303 \mathrm{~K}$ and $20 \mathrm{kPa}$, which is a typical value for $\mathrm{CO}_{2}$ partial pressure in flue gas during the adsorption step of VSA and TSA processes. The same functionalized adsorbent (having a nominal [bmim] [Ac] content of $30 \% w / w$ ) showed a $\mathrm{CO}_{2} / \mathrm{N}_{2}$ selectivity of more than 18 times higher than that of the parent MOF at $323 \mathrm{~K}$ and $10 \mathrm{kPa}$. Unfortunately, cyclic adsorption-desorption test details (which, by the way, do not seem particularly encouraging) were provided only for samples with a nominal [bmim][Ac] content of $20 \% w / w$.

As in the previously cited work, Zeeshan et al. impregnated ZIF-8 with 1-n-butyl-3-methylimidazolium thiocyanate ([bmim][SCN]) [74]. In this case, the only attained improvement with respect to the parent MOF was the increase in both $\mathrm{CO}_{2} / \mathrm{N}_{2}$ and $\mathrm{CO}_{2} / \mathrm{CH}_{4}$ selectivity. Indeed, following the functionalization procedure, the $\mathrm{CO}_{2}$ adsorption capacity decreased across the whole pressure range considered. Moreover, no indication about the regeneration capabilities of the impregnated adsorbent was provided. 
A more complete study was carried out by Ferreira et al., who functionalized ZIF-8 with 10 different types of ionic liquids [75]. In all these cases, $\mathrm{CO}_{2}$ adsorption turned out to be reversible (i.e., the adsorbent turned out to be regenerable) in the whole pressure range considered. Moreover, even though all impregnated adsorbents showed lower $\mathrm{CO}_{2}$ adsorption capacities with respect to the parent MOF, most of them also showed higher $\mathrm{CO}_{2} / \mathrm{CH}_{4}$ selectivities.

Despite the reported studies about the functionalization of ZIF-8 for $\mathrm{CO}_{2}$ adsorption, it must be highlighted that, in a very recent work [76], Idris et al. chose this MOF in its pristine form to compare it with four other different adsorbents in an actual PSA process. As a result, ZIF-8 turned out to perform worse than a cheaper adsorbent (i.e., a specific palm kernel shell—derived activated carbon) both in terms of $\mathrm{CO}_{2}$ purity and recovery during the column regeneration step.

As has already been pointed out, functionalization with amine-containing agents does not only increase the $\mathrm{CO}_{2}$ adsorption performances of MOFs per se, but it can further increase them in the presence of water vapor. The latter, extremely peculiar feature also seems to be shown (literature data are conflicting) by specific unfunctionalized MOFs, one of which is the variant of PCN-250 containing only Fe in its metal clusters. This MOF, also known as MIL-127, is commercially available under different names such as Porolite ${ }^{\circledR}$ F3, AYRSORB ${ }^{\circledR}$ F250, and CONEKTIC ${ }^{\circledR}$ F250. In 2017 [46], Wongsakulphasatch et al. investigated the performance of PCN-250 $\left(\mathrm{Fe}_{3}\right)$ on $\mathrm{CO}_{2}$ separation from a $\mathrm{CO}_{2} / \mathrm{N}_{2}$ binary mixture under simulated post-combustion conditions. As usually expected, the presence of moisture in the gas mixture negatively affected $\mathrm{CO}_{2}$ adsorption capacity. This result has been surprisingly denied by Chen et al. [47], who found that the $\mathrm{CO}_{2}$ dynamic adsorption capacity of PCN-250 $\left(\mathrm{Fe}_{3}\right)$ increased by $54.2 \%$ under $50 \%$ relative humidity $(\mathrm{RH})$ conditions with respect to that under dry conditions. Interestingly, the same authors also compared the IAST selectivities for $\mathrm{CO}_{2} / \mathrm{N}_{2}$ and $\mathrm{CO}_{2} / \mathrm{CH}_{4}$ separations, finding that PCN-250 $\left(\mathrm{Fe}_{3}\right)$ was surely more suitable for flue gas treatment than for natural gas upgrading processes. Eventually, they also highlighted very good regeneration capabilities for the same MOF.

The last of the commercially available MOFs [60] that were thoroughly studied for their potentialities in $\mathrm{CO}_{2}$ adsorption applications is the zirconium terephthalate known as UiO-66. In 2011, Yang et al. combined experimental measurements and molecular modeling to understand the adsorption of $\mathrm{CO}_{2}$ and $\mathrm{CH}_{4}$ in UiO-66 [48], finding that this MOF is very promising for natural gas upgrading because of its good $\mathrm{CO}_{2} / \mathrm{CH}_{4}$ selectivity, easy regenerability, and stability under various conditions (e.g., in the presence of water vapor). Still regarding $\mathrm{CO}_{2} / \mathrm{CH}_{4}$ separation, Cavka et al. compared the adsorption equilibrium of $\mathrm{CO}_{2}$ and $\mathrm{CH}_{4}$ on UiO-66 with those on two other $\mathrm{Zr}$-based MOFs, isoreticular with UiO-66 [49]. The latter adsorbent turned out to be the worst performing in terms of both $\mathrm{CO}_{2}$ adsorption capacity and $\mathrm{CO}_{2} / \mathrm{CH}_{4}$ selectivity. To the best of our knowledge, none of the other two MOFs investigated in that work are currently mass-produced and sold on a global scale (i.e., they are not eligible for a potential rapid implementation in fixed bed adsorption columns).

In 2013 [50], Andersen et al. evaluated the performances of $\mathrm{UiO}-66$ as a $\mathrm{CO}_{2}$ adsorbent in a post-combustion VSA process, achieving $\mathrm{CO}_{2}$ purity values around $60 \%$ and $\mathrm{CO}_{2}$ recovery values up to $70 \%$. Moreover, cyclic adsorption-desorption experiments showed that $\mathrm{CO}_{2}$ adsorption capacity was reduced by approximately $25 \%$ in the presence of water vapor, while it was not reduced at all when the same tests were carried out feeding a dry gas stream.

Analogously, Kim et al. studied $\mathrm{CO}_{2} / \mathrm{N}_{2}$ separation using UiO-66 under conditions that can usually be found in PSA processes [51], obtaining quite interesting values of $\mathrm{CO}_{2}$ selectivity. Moreover, a reproducible adsorption behavior was observed during cyclic adsorption/desorption runs. The latter aspect of $\mathrm{CO}_{2}$ adsorption on UiO-66 was thoroughly investigated by $\mathrm{Hu}$ et al., who found that equilibrium adsorption capacity remained almost unaltered after 500 cyclic $\mathrm{CO}_{2}$ adsorption-desorption tests (unlike what happens, e.g., to $\mathrm{Cu}$-BTC) [77]. The authors managed to measure the elastic modulus of the UiO-66 framework by means of multifrequency atomic force microscopy (MAFM), finding a higher value with respect to other MOFs. This observation was correlated to the capability of UiO-66 to withstand a huge number of adsorption-desorption cycles without suffering structural damages and thus entirely keeping its adsorbent properties. 
Very recently [78], Edubilli et al. carried out the "litmus test" for using UiO-66 in flue gas treatment by setting up a combined pressure-vacuum swing adsorption (PVSA) column packed with this $\mathrm{MOF}$. The obtained $\mathrm{CO}_{2}$ purity and recovery values were close to those observed using other MOFs; moreover, as already highlighted, UiO-66 is much more stable than similar adsorbents when undergoing numerous adsorption-desorption cycles. Furthermore, the aforementioned $\mathrm{CO}_{2}$ purity value does not even remotely meet that needed by transportation requirements, probably because of the reported single column setup that is known to perform much worse than a multi-bed setup [78].

With regard to its potential use in natural gas upgrading, UiO-66 also showed clear limits when used in an actual double-column PSA process [79]. Indeed, the obtained values of $\mathrm{CO}_{2}$ purity and recovery turned out to be lower than those obtained with a cheaper palm kernel shell-derived activated carbon. Nevertheless, for the sake of clarity, it must be noticed that UiO-66 as prepared in the latter work did not seem to have followed a completely correct synthesis route as detectable from the textural characterization results.

Like other MOFs already reported in Table 1, UiO-66 was also subject to different functionalization attempts aimed at increasing its $\mathrm{CO}_{2}$ adsorption performances. As an example, Hon Lau et al. almost doubled the $\mathrm{CO}_{2}$ adsorption capacity of UiO-66 by the post-synthetic exchange of framework $\mathrm{Zr}$ by $\mathrm{Ti}$ [52]. Unfortunately, no information about $\mathrm{CO}_{2}$ selectivity against other gases and about adsorbent regeneration was given.

In 2014, Hong et al. adopted the complementary approach with respect to the latter cited paper (i.e., they exchanged a fraction of the ligand terephthalate moieties in UiO-66 with adipate counterparts [53]). As a result, all of the performance parameters essential to natural gas upgrading ( $\mathrm{CO}_{2}$ adsorption capacity, $\mathrm{CO}_{2} / \mathrm{CH}_{4}$ selectivity, and adsorbent regenerability) improved when compared to those of the parent MOF.

With regard to the category of functionalization with amine compounds, $\mathrm{Li}$ et al. grafted ethanolamine (EA) molecules on UiO-66 CUSs and investigated the resulting consequences on $\mathrm{CO}_{2}$ adsorption [54]. As already observed in similar cases, the overall $\mathrm{CO}_{2}$ adsorption capacity decreased with respect to the pristine $\mathrm{MOF}$, but $\mathrm{CO}_{2}$ affinity significantly increased. Moreover, the authors observed an extremely high $\mathrm{CO}_{2} / \mathrm{N}_{2}$ selectivity for the EA-functionalized adsorbent, which encouraged them in performing breakthrough tests both with dry and humid feeds, finding complete retention of $\mathrm{CO}_{2} / \mathrm{N}_{2}$ separation performances even in high moisture conditions.

Similar to what has often been experimented with mesoporous silicates [12-14,16], Xian et al. impregnated UiO-66 with polyethylenimine (PEI) [55]. With respect to the pristine MOF, the adsorbent sample containing the optimal PEI amount showed increased $\mathrm{CO}_{2}$ uptakes across the whole sub-atmospheric pressure range. Moreover, PEI-functionalized UiO-66 attained a very good dynamic $\mathrm{CO}_{2} / \mathrm{CH}_{4}$ selectivity that further increased in the presence of a humid feed. Eventually, cyclic adsorption-desorption tests suggested that the $\mathrm{CO}_{2}$ adsorption capacity of the PEI-impregnated MOF can be fully recovered after regeneration.

As in the case of Mg-MOF-74 and ZIF-8, UiO-66 was also subject to functionalization with TEPA [56], resulting in higher dynamic $\mathrm{CO}_{2}$ adsorption capacity with respect to the parent MOF. Moreover, cyclic breakthrough tests suggested that the functionalized adsorbent can be fully and easily regenerated. Unfortunately, no information about $\mathrm{CO}_{2}$ selectivity against other gases was given.

Eventually, among the functionalization routes already contemplated in Table 1, lithium doping was also considered for increasing the $\mathrm{CO}_{2}$ adsorption performances of UiO-66. As reported by Niu et al. [57], Li-doped UiO-66 exhibited highly enhanced $\mathrm{CO}_{2}$ adsorption capacity and $\mathrm{CO}_{2} / \mathrm{N}_{2}$ IAST selectivity with respect to the parent MOF. Moreover, the $\mathrm{CO}_{2}$ adsorption isotherm at ambient temperature turned out to be completely reversible, thus suggesting the possibility of fully regenerating the adsorbent in cyclic operations.

A crucial, still overlooked aspect downstream from the discussion illustrated above regards the need of shaped adsorbents for packing industrial scale beds, whereas all the examined materials were initially produced in powder form. In fact, commercial MOF providers offer powder shaping 
as an additional service [80], thus relieving the end user from this laborious task. In order to be of any practical use inside adsorption columns, MOF powders need to be processed by means of classical methods such as granulation and pelletization [81]. In both the latter cases, adsorbent shaping comes with a cost (i.e., it negatively affects the structural/textural properties of MOFs). The techniques used for shaping MOFs thus demand further research in order to optimize such manufacturing processes [82-84]. The most detrimental side effects that must still be minimized are the collapse of the adsorbent crystalline lattice, the reduced access to its pore structure, and the diffusion limitations of shaped bodies due to non-optimal void fractions between the primary powders [85].

A last, even more crucial issue regarding the suitability of using MOFs in actual industrial $\mathrm{CO}_{2}$ adsorption processes regards the comparison between the costs and the benefits that such a technological shift would bring along. Unfortunately, current analyses available in the literature seem to point out that, despite their declared performance superiority, MOFs cannot compare to much cheaper traditional adsorbents. As an example (more systematic than others already cited [76,79]), Danaci et al. assessed 22 different MOFs (some of which are among the ones listed in Table 1) against specific performance constraints and cost in $\mathrm{CO}_{2}$ capture from flue gas using PVSA [86]. At the end of such a significant screening, the MOF that showed the best performance and lowest cost was a still-commercially-unavailable one (i.e., UTSA-16), although its performance was in line with a much cheaper 13X zeolite. It is hoped that studies like the latter one provide specific directions for material scientists to design MOF adsorbents with more focus on the actual process needs than on the discovery of new structures per se.

\section{MOFs for Other Adsorption Processes Significant for the Atmospheric Environment}

As outlined in Section 1, in addition to $\mathrm{CO}_{2}$, there are other greenhouse gases and other gas typologies whose emissions, for various reasons, represent a significant "wound" for the Earth's atmosphere. Additionally, in these cases, adsorption represents the cleanest way for capturing such pollutants from end-of-process gas streams, and MOFs could be considered as a valid choice as materials for adsorption column packing.

\subsection{Adsorption of Sulfur and Nitrogen Oxides}

When emitted into the atmosphere, sulfur and nitrogen oxides (namely, $\mathrm{SO}_{\mathrm{x}}$ and $\mathrm{NO}_{\mathrm{x}}$ ) contribute to ground-level ozone formation and are responsible for eutrophication, reduction in water quality and, eventually, species richness. They are also associated with adverse effects on human health as high concentrations cause respiratory illnesses. Both $\mathrm{NO}_{\mathrm{x}}$ and $\mathrm{SO}_{\mathrm{x}}$ are combustion products that are emitted into the atmosphere within flue gas. Indeed, most anthropogenic $\mathrm{SO}_{\mathrm{x}}$ and $\mathrm{NO}_{\mathrm{x}}$ emissions emerge from the combustion of coal and heavy oil. Moreover, other industrial processes are also specifically responsible for significant $\mathrm{SO}_{2}$ emissions $[87,88]$.

During the last 15 years, the scientific community has shown a growing interest in the attempt to capture industrially originating $\mathrm{SO}_{x}$ and $\mathrm{NO}_{x}$ before their emission into the atmosphere. MOFs, due to their great sorption capacities and their selectivity in capturing a large number of toxic and pollutant gases [89-93], are thus considered promising candidates for packing $\mathrm{SO}_{\mathbf{x}}$ and $\mathrm{NO}_{\mathrm{x}}$ adsorption columns. In this regard, the most interesting results are summarized in Table 3. 
Table 3. MOFs potentially suitable for $\mathrm{SO}_{x}$ and $\mathrm{NO}_{\mathrm{x}}$ adsorption.

\begin{tabular}{|c|c|c|c|}
\hline MOF Type & Adsorbate & $\begin{array}{l}\text { Adsorption Capacity }{ }^{1}, \text { mol/kg (Reported } \\
\text { Working Conditions, } T \text {, and } p)^{2}\end{array}$ & Reference \\
\hline $\mathrm{Cu}-\mathrm{BTC}$ & $\mathrm{SO}_{2}$ & $\begin{array}{c}0.71 \text { (breakthrough, } \mathrm{SO}_{2} / \mathrm{O}_{2} / \mathrm{He} \text { mixture, } \\
{\left[\mathrm{SO}_{2}\right]=50 \mathrm{ppm}, 773 \mathrm{~K} \text { ) }}\end{array}$ & \multirow{2}{*}{ [94] } \\
\hline Ba-Doped Cu-BTC & $\mathrm{SO}_{2}$ & $\begin{array}{l}2.71 \text { (breakthrough, } \mathrm{SO}_{2} / \mathrm{O}_{2} / \mathrm{He} \text { mixture, } \\
{\left[\mathrm{SO}_{2}\right]=50 \mathrm{ppm}, 773 \mathrm{~K} \text { ) }}\end{array}$ & \\
\hline MOF-177 & $\mathrm{SO}_{2}$ & $25.70(293 \mathrm{~K}, 100 \mathrm{kPa})$ & [95] \\
\hline $\mathrm{UiO}-66$ & $\mathrm{NO}_{2}$ & $\begin{array}{c}1.59 \text { (breakthrough, } \mathrm{NO}_{2} / \mathrm{N}_{2} \text { /air mixture, } \\
{\left[\mathrm{NO}_{2}\right]=1000 \mathrm{ppm}, 298 \mathrm{~K} \text { ) }}\end{array}$ & [96] \\
\hline
\end{tabular}

\footnotetext{
${ }^{1}$ Where not explicitly reported in the cited papers, adsorption capacity values were extracted from plots using reverse engineering software. ${ }^{2}$ Where not explicitly reported, working conditions imply the collection of single-component adsorption isotherms.
}

In 2005, Dathe et al. studied the $\mathrm{SO}_{2}$ adsorption properties of pristine $\mathrm{Cu}-\mathrm{BTC}$ and $\mathrm{Cu}-\mathrm{BTC}$ samples impregnated with different barium salts [94]. $\mathrm{SO}_{2}$ capture properties were evaluated under dynamic conditions at high temperatures. When the adsorption temperature is non-critical for the thermal stability of $\mathrm{Cu}-\mathrm{BTC}, \mathrm{SO}_{2}$ capture can be described as a combination of physisorption processes on $\mathrm{Cu}$ active sites and the formation of Ba-sulfates, as $\mathrm{Cu}$ is still integrated into the MOF. At higher temperatures, the MOF is thermally decomposed, which leads to the formation of isolated Cu species that act as $\mathrm{SO}_{2}$ chemisorption active sites, thus forming $\mathrm{Cu}$-sulfates. Such adsorbents have turned out to be non-regenerable, thus resulting in being poorly attractive for industrial purposes.

More recently, Brandt et al. presented $\mathrm{SO}_{2}$ adsorption studies for three different MOFs (i.e., MOF-177, $\mathrm{NH}_{2}$-functionalized MIL-125 (Ti) and MIL-160 [95]). Among these adsorbents, the only one potentially implementable in industrial applications in the short/medium period, MOF-177, showed by far the highest $\mathrm{SO}_{2}$ adsorption capacity, with a remarkable uptake of $25.70 \mathrm{~mol} / \mathrm{kg}$ at atmospheric pressure and $293 \mathrm{~K}$. The $\mathrm{SO}_{2}$ adsorption isotherm on MOF-177 at $293 \mathrm{~K}$, according to the International Union of Pure and Applied Chemistry (IUPAC), turned out to be Type V, which implies quite a low adsorbent-adsorbate affinity. Moreover, the same isotherms proved to be non-reversible, thus casting a shadow on the adsorbent regeneration possibilities.

Eventually, Ebrahim et al. studied the performances of UiO-66 as a $\mathrm{NO}_{2}$ adsorbent at ambient temperature in either dry or humid conditions [96]. As expected, the breakthrough adsorption capacity in dry conditions turned out to be far better than that observed in the presence of moisture. Interestingly, such behavior was reversed in the case of the still-commercially-unavailable UiO-67 [96]. Unfortunately, no information was provided about the adsorbent regeneration, even though Fourier-transform infrared (FTIR) characterization suggested a chemisorption-type behavior, especially in the presence of water vapor.

\subsection{Adsorption of Volatile Organic Compounds}

Volatile organic compounds (VOCs) are a major group of air pollutants, potentially leading to photochemical smog, carcinogenesis, teratogenesis, and mutagenesis, which endanger both the ecological environment and human health [97,98]. Anthropogenic VOC emissions emerge from a wide range of industrial processes including crude oil and natural gas exploration, petroleum refining, and basic chemical raw materials manufacturing [99]. Despite the immense amount of research reported regarding MOF adsorbents, literature about the adsorption of VOCs on MOFs is relatively scarce. The results regarding MOFs produced on an industrial scale and commercially available are mostly summarized in Table 4. 
Table 4. MOFs potentially suitable for the adsorption of volatile organic compounds (VOCs).

\begin{tabular}{|c|c|c|c|}
\hline MOF Type & Adsorbate & $\begin{array}{l}\text { Adsorption Capacity }{ }^{1}, \mathrm{~mol} / \mathrm{kg} \text { (Reported } \\
\text { Working Conditions, } T \text { and } p)^{2}\end{array}$ & Reference \\
\hline \multirow{8}{*}{ MOF-177 } & acetone & $8.30(298 \mathrm{~K}, 10.83 \mathrm{kPa})$ & \multirow{8}{*}{ [100] } \\
\hline & benzene & $8.82(298 \mathrm{~K}, 4.88 \mathrm{kPa})$ & \\
\hline & toluene & $3.77(298 \mathrm{~K}, 1.44 \mathrm{kPa})$ & \\
\hline & ethylbenzene & $2.13(298 \mathrm{~K}, 0.39 \mathrm{kPa})$ & \\
\hline & m-xylene & $1.92(298 \mathrm{~K}, 0.33 \mathrm{kPa})$ & \\
\hline & o-xylene & $1.97(298 \mathrm{~K}, 0.34 \mathrm{kPa})$ & \\
\hline & p-xylene & $1.78(298 \mathrm{~K}, 0.32 \mathrm{kPa})$ & \\
\hline & ethenylbenzene & $1.61(298 \mathrm{~K}, 0.23 \mathrm{kPa})$ & \\
\hline \multirow{2}{*}{ Al-fumarate } & dichloromethane & $3.40(298 \mathrm{~K}, 44.70 \mathrm{kPa})$ & \multirow{2}{*}{ [101] } \\
\hline & trichloromethane & $2.51(298 \mathrm{~K}, 21.44 \mathrm{kPa})$ & \\
\hline $\mathrm{UiO}-66$ & toluene & $\begin{array}{l}1.64 \text { (breakthrough, toluene } / \mathrm{O}_{2} / \text { argon } \\
\text { mixture, [toluene] }=1000 \mathrm{ppm}, 298 \mathrm{~K} \text { ) }\end{array}$ & [102] \\
\hline
\end{tabular}

${ }^{1}$ Where not explicitly reported in the cited papers, adsorption capacity values were extracted from plots using reverse engineering software. ${ }^{2}$ Where not explicitly reported, working conditions imply the collection of single-component adsorption isotherms.

In 2013, Yang et al. tested the adsorption properties of MOF-177 with several VOCs [100]. The influence of humidity on adsorption was also examined. Adsorption of VOCs sharply decreased once the $\mathrm{RH}$ increased from $0 \%$ to $50 \%$. However, the decrease of adsorption with $\mathrm{RH}$ was insignificant when the RH increased from $50 \%$ to $90 \%$. This is probably due to the adsorption of water molecules, which compete with VOCs for adsorption and cause blockages impeding the access of VOC molecules to the pores. Moreover, the crystal structure of MOF-177 is reported to be labile in the presence of moisture [103], thus suggesting that such an adsorbent should not be exposed for a long time to somewhat high $\mathrm{RH}$, regardless of the specific application.

In 2016, Vellingiri et al. investigated the adsorption behavior of a mixture of 14 volatile and semi-volatile organic compounds on Cu-BTC at ambient conditions (breakthrough experiments, total VOC feed concentration $\approx 100 \mathrm{ppb}$ ) [104]. Such a MOF revealed a total adsorption capacity (i.e., $7.2 \mathrm{wt} \%$ ) that was also higher than that shown by three different commercial non-MOF adsorbents. The experimental results suggest that the adsorption mechanism for $\mathrm{Cu}$-BTC was most favorable due to the presence of CUSs. However, the adsorption was found to be irreversible, thus limiting a possible industrial use of the process.

Another MOF that has been studied in terms of VOC adsorption is the Al-fumarate commercialized under brands like Basolite ${ }^{\circledR}$ A520 and Porolite ${ }^{\circledR}$ A1 [60]. In 2017, Zhou et al. tested Al-fumarate for the adsorption of dichloromethane (DCM) and trichloromethane (TCM) [101]. The experiments showed high DCM adsorption capacity and DCM/TCM selectivity. The latter phenomenon was attributed to the different sizes of the adsorbate molecules. Indeed, the smaller DCM molecules could more easily access the pore channels of Al-fumarate and can take advantage of more adsorption active sites than TCM. Unfortunately, no indication of the regeneration capabilities of the adsorbent was provided.

Eventually, Zhang et al. studied the toluene adsorption performances of UiO-66 [102]. In this paper, it was demonstrated that moisture has a significantly negative effect on the toluene adsorption capacity, indicating a strongly competitive adsorption process between toluene and water vapor. Very interestingly, the adsorbent turned out to be fully regenerable under thermal treatment and to completely keep its adsorption capacity after three consecutive adsorption/desorption cycles.

\subsection{Adsorption of Fluorinated Gases}

Historically, another class of gas emissions that are considered extremely harmful for the atmosphere is that including fluorinated compounds. In particular, chlorofluorocarbons (CFCs) constitute a serious threat to the stratospheric ozone layer. During the last decades, the progressive 
substitution of CFCs with other types of service fluids in refrigeration processes has allowed for the significant recovery of the functionality of the planetary natural UV shield. There are other categories of fluorinated gases that should be considered highly dangerous for the Earth's atmosphere. Among them, halogenated general anesthesia gases (HGAGs) represent an emerging threat due to their worldwide growing uncontrolled discharge [105]. Indeed, Cl-containing HGAGs (e.g., enflurane and isoflurane) are also classified as CFCs, while sevoflurane, desflurane, and (again) isoflurane are characterized by a global warming potential (GWP) that is three orders of magnitude higher than that of $\mathrm{CO}_{2}$ [106]. Among the convenient technologies for handling emissions of HGAGs, adsorption-based ones are recognized as the most effective [107]. Indeed, non-metabolized anesthetic vapors can be captured in canisters that act as adsorption mini-columns on the vent line of the breathing system connected to the patient. Currently, studies about the potential use of MOFs for packing such canisters are quite rare. To the best of our knowledge, the only paper that deals with this topic and envisages the use of an already commercially available adsorbent reported the sevoflurane (SF) adsorption properties of MOF-177 [108]. Despite the impressive SF adsorption capacity and affinity showed by this material, its actual implementation as an anesthetic scavenger is strongly undermined due to the presence of moisture in the vent line of breathing systems [103].

In truth, the only MOF that proved to be practically suitable for HGAG capture is the chromium variant of MIL-101, which is not currently available in large quantities as a commercial product. Indeed, MIL-101 showed a significantly higher SF equilibrium adsorption capacity when compared to a reference adsorbent conventionally used for HGAG scavenging [109]. Moreover, when shaped and column-packed, MIL-101 revealed a much higher SF/ $\mathrm{H}_{2} \mathrm{O}$ selectivity with respect to the aforementioned reference adsorbent, which suffered from "roll-up" effects when the test column reached saturation [110]. Under the same dynamic conditions (which obviously include a significant presence of moisture in the feed), the same MOF also showed a much higher performance stability when compared with the reference adsorbent after several adsorption/desorption cycles [111]. Unfortunately, as already outlined, such technologically-relevant results are not destined to improve the performances of the HGAG scavenging systems used in operating rooms (at least for the moment) due to the impossibility of large-scale MIL-101 supplies.

\section{Conclusions}

Regarding adsorption-based technologies for atmospheric emission control, there is a strong evidence of how MOFs are still far away from passing their "graduation exam". It is undeniable that MOFs can be specifically designed for adsorption processes otherwise unimaginable for classical materials [112-115]. With regard to consolidated, packed column-based adsorption processes, there is a wide gap between laboratory results and industrial implementation due to different factors. First, even when a MOF that performs well in a specific process (e.g., $\mathrm{CO}_{2}$ adsorption) is commercially available in large quantities, economic observations still make designers tend toward more traditional adsorbents (e.g., zeolites and activated carbons). Indeed, the cost per mass unit of commercial MOFs is basically orders of magnitude higher than that of other materials, whose industrial use is already well-established. Moreover, there are cases (like adsorption processes for HGAG scavenging) in which a specific MOF remarkably outperforms currently employed adsorbents, but it is not industrially produced, thus strongly limiting its possibilities of large-scale use. To overcome such limitations, it is to be hoped that the chemical industry will be able to provide more and more mass-produced MOFs at increasingly competitive costs in the future.

Author Contributions: Conceptualization, N.G.; methodology, N.G. and D.C.; validation, D.C.; writing-review and editing, N.G., A.P. and D.C. All authors have read and agreed to the published version of the manuscript.

Funding: This research received no external funding.

Conflicts of Interest: The authors are among the inventors who, in 2017, signed the U.S. Patent no. 9737873. This patent, entitled "Adsorbent for Halogenated Anesthetics", deals with one of the subjects addressed in 
this paper. The authors have neither financial nor other interest relationships with the company (Blue-Zone Technologies Ltd., Concord, CA) that is the actual assignee of such a patent.

\section{References}

1. IPCC. Climate Change 2014: Synthesis Report. Contribution of Working Groups I, II and III to the Fifth Assessment Report of the Intergovernmental Panel on Climate Change; Core Writing Team, Pachauri, R.K., Meyer, L.A., Eds.; IPCC: Geneva, Switzerland, 2014; p. 151.

2. Wan, X.; Zhang, Z. Climate warming and humans played different roles in triggering Late Quaternary extinctions in east and west Eurasia. Proc. R. Soc. B 2017, 284, 20162438. [CrossRef]

3. Mersmann, A.; Fill, B.; Hartmann, R.; Maurer, S. The potential of energy saving by gas-phase adsorption processes. Chem. Eng. Technol. 2000, 23, 937-944. [CrossRef]

4. Broom, D.P.; Thomas, K.M. Gas adsorption by nanoporous materials: Future applications and experimental challenges. MRS Bull. 2013, 38, 412-421. [CrossRef]

5. Li, J.-R.; Kuppler, R.J.; Zhou, H.-C. Selective gas adsorption and separation in metal-organic frameworks. Chem. Soc. Rev. 2009, 38, 1477-1504. [CrossRef] [PubMed]

6. Raynaud, D.; Barnol, J.M. An Antarctic ice core reveals atmospheric $\mathrm{CO}_{2}$ variations over the past few centuries. Nature 1985, 315, 309-311. [CrossRef]

7. Climate Change: Atmospheric Carbon Dioxide. Available online: https://www.climate.gov/news-features/ understanding-climate/climate-change-atmospheric-carbon-dioxide (accessed on 8 January 2020).

8. Schneider, S. The greenhouse effect: Science and policy. Science 1989, 243, 771-781. [CrossRef]

9. Jiang, L.; Gonzalez-Diaz, A.; Ling-Chin, J.; Roskilly, A.P.; Smallbone, A.J. Post-combustion $\mathrm{CO}_{2}$ capture from a natural gas combined cycle power plant using activated carbon adsorption. Appl. Energy 2019, 245, 1-15. [CrossRef]

10. Oreggioni, G.D.; Brandani, S.; Luberti, M.; Baykan, Y.; Friedrich, D.; Ahn, H. $\mathrm{CO}_{2}$ capture from syngas by an adsorption process at a biomass gasification $\mathrm{CHP}$ plant: Its comparison with amine-based $\mathrm{CO}_{2}$ capture. Int. J. Greenhouse Gas Control 2015, 35, 71-81. [CrossRef]

11. Gargiulo, N.; Shibata, K.; Peluso, A.; Aprea, P.; Valente, T.; Pezzotti, G.; Shiono, T.; Caputo, D. Reinventing rice husk ash: Derived $\mathrm{NaX}$ zeolite as a high-performing $\mathrm{CO}_{2}$ adsorbent. Int. J. Environ. Sci. Technol. 2018, 15, 1543-1550. [CrossRef]

12. Gargiulo, N.; Pepe, F.; Caputo, D. $\mathrm{CO}_{2}$ adsorption by functionalized nanoporous materials: A review. J. Nanosci. Nanotechnol. 2014, 14, 1811-1822. [CrossRef]

13. Gargiulo, N.; Pepe, F.; Caputo, D. Modeling carbon dioxide adsorption on polyethylenimine-functionalized TUD-1 mesoporous silica. J. Colloid Interface Sci. 2012, 367, 348-354. [CrossRef] [PubMed]

14. Gargiulo, N.; Peluso, A.; Aprea, P.; Pepe, F.; Caputo, D. $\mathrm{CO}_{2}$ Adsorption on polyethylenimine-functionalized SBA-15 mesoporous silica: Isotherms and modeling. J. Chem. Eng. Data 2014, 59, 896-902. [CrossRef]

15. Gargiulo, N.; Macario, A.; Iucolano, F.; Giordano, G.; Caputo, D. Modeling the adsorption of $\mathrm{CO}_{2} / \mathrm{N}_{2}$ mixtures on siliceous nanoporous materials. Sci. Adv. Mater. 2015, 7, 258-263. [CrossRef]

16. Gargiulo, N.; Verlotta, A.; Peluso, A.; Aprea, P.; Caputo, D. Modeling the performances of a $\mathrm{CO}_{2}$ adsorbent based on polyethylenimine-functionalized macro-/mesoporous silica monoliths. Microporous Mesoporous Mater. 2015, 215, 1-7. [CrossRef]

17. Ghanbari, T.; Abnisa, F.; Wan Daud, W.M.A. A review on production of metal organic frameworks (MOF) for $\mathrm{CO}_{2}$ adsorption. Sci. Total Environ. 2020, 707, 135090. [CrossRef] [PubMed]

18. Saqib, S.; Rafiq, S.; Chawla, M.; Saeed, M.; Muhammad, N.; Khurram, S.; Majeed, K.; Khan, A.L.; Ghauri, M.; Jamil, F.; et al. Facile $\mathrm{CO}_{2}$ separation in composite membranes. Chem. Eng. Technol. 2019, 42, 30-44. [CrossRef]

19. Saha, D.; Bao, Z.; Jia, F.; Deng, S. Adsorption of $\mathrm{CO}_{2}, \mathrm{CH}_{4}, \mathrm{~N}_{2} \mathrm{O}$, and $\mathrm{N}_{2}$ on MOF-5, MOF-177, and Zeolite 5A. Environ. Sci. Technol. 2010, 44, 1820-1826. [CrossRef]

20. Ullah, S.; Bustam, M.A.; Assiri, M.A.; Al-Sehemi, A.G.; Sagir, M.; Abdul Kareem, F.A.; Elkhalifah, A.E.I.; Mukhtar, A.; Gonfa, G. Synthesis, and characterization of metal-organic frameworks -177 for static and dynamic adsorption behavior of $\mathrm{CO}_{2}$ and $\mathrm{CH}_{4}$. Microporous Mesoporous Mater. 2019, 288, 109569. [CrossRef] 
21. Mason, J.A.; Sumida, K.; Herm, Z.R.; Krishna, R.; Long, J.R. Evaluating metal-organic frameworks for post-combustion carbon dioxide capture via temperature swing adsorption. Energy Environ. Sci. 2011, 4, 3030-3040. [CrossRef]

22. Mohamedali, M.; Henni, A.; Ibrahim, H. Investigation of $\mathrm{CO}_{2}$ capture using acetate-based ionic liquids incorporated into exceptionally porous metal-organic frameworks. Adsorption 2019, 25, 675-692. [CrossRef]

23. Aprea, P.; Caputo, D.; Gargiulo, N.; Iucolano, F.; Pepe, F. Modeling carbon dioxide adsorption on Microporous substrates: Comparison between Cu-BTC metal-organic framework and 13X Zeolitic molecular sieve. J. Chem. Eng. Data 2010, 55, 3655-3661. [CrossRef]

24. Hamon, L.; Jolimaître, E.; Pirngruber, G.D. $\mathrm{CO}_{2}$ and $\mathrm{CH}_{4}$ separation by adsorption using Cu-BTC metal-organic framework. Ind. Eng. Chem. Res. 2010, 49, 7497-7503. [CrossRef]

25. Ye, S.; Jiang, X.; Ruan, L.-W.; Liu, B.; Wang, Y.-M.; Zhu, J.-F.; Qiu, L.-G. Post-combustion $\mathrm{CO}_{2}$ capture with the HKUST-1 and MIL-101(Cr) metal-organic frameworks: Adsorption, separation and regeneration investigations. Microporous Mesoporous Mater. 2013, 179, 191-197. [CrossRef]

26. Kloutse, F.A.; Hourri, A.; Natarajan, S.; Benard, P.; Chahine, R. Systematic study of the excess and the absolute adsorption of $\mathrm{N}_{2} / \mathrm{H}_{2}$ and $\mathrm{CO}_{2} / \mathrm{H}_{2}$ mixtures on Cu-BTC. Adsorption 2019, 25, 941-950. [CrossRef]

27. Mohamedali, M.; Henni, A.; Ibrahim, H. Markedly improved $\mathrm{CO}_{2}$ uptake using imidazolium-based ionic liquids confined into HKUST-1 frameworks. Microporous Mesoporous Mater. 2019, 284, 98-110. [CrossRef]

28. Zhou, L.; Niu, Z.; Jin, X.; Tang, L.; Zhu, L. Effect of Lithium Doping on the structures and $\mathrm{CO}_{2}$ adsorption properties of metal-organic frameworks HKUST-1. ChemistrySelect 2018, 3, 12865-12870. [CrossRef]

29. Bao, Z.; Yu, L.; Ren, Q.; Lu, X.; Deng, S. Adsorption of $\mathrm{CO}_{2}$ and $\mathrm{CH}_{4}$ on a magnesium-based metal organic framework. J. Colloid Interface Sci. 2011, 353, 549-556. [CrossRef]

30. Herm, Z.R.; Krishna, R.; Long, J.R. $\mathrm{CO}_{2} / \mathrm{CH}_{4}, \mathrm{CH}_{4} / \mathrm{H}_{2}$ and $\mathrm{CO}_{2} / \mathrm{CH}_{4} / \mathrm{H}_{2}$ separations at high pressures using $\mathrm{Mg}_{2}$ (dobdc). Microporous Mesoporous Mater. 2012, 151, 481-487. [CrossRef]

31. Remy, T.; Peter, S.A.; Van Der Perre, S.; Valvekens, P.; De Vos, D.E.; Baron, G.V.; Denayer, J.F.M. Selective dynamic $\mathrm{CO}_{2}$ separations on Mg-MOF-74 at low pressures: A detailed comparison with 13X. J. Phys. Chem. C 2013, 117, 9301-9310. [CrossRef]

32. Moon, H.-S.; Moon, J.-H.; Chun, D.H.; Park, Y.C.; Yun, Y.N.; Sohail, M.; Baek, K.; Kim, H. Synthesis of $\left[\mathrm{Mg}_{2}(\mathrm{DOBDC})(\mathrm{DMF})_{2}\right] @$ polystyrene composite and its carbon dioxide adsorption. Microporous Mesoporous Mater. 2016, 232, 161-166. [CrossRef]

33. Cao, Y.; Song, F.; Zhao, Y.; Zhong, Q. Capture of carbon dioxide from flue gas on TEPA-grafted metal-organic framework $\mathrm{Mg}_{2}$ (dobdc). J. Environ. Sci. 2013, 25, 2081-2087. [CrossRef]

34. Su, X.; Bromberg, L.; Martis, V.; Simeon, F.; Huq, A.; Hatton, T.A. Postsynthetic functionalization of Mg-MOF-74 with Tetraethylenepentamine: Structural characterization and enhanced $\mathrm{CO}_{2}$ adsorption. ACS Appl. Mater. Interfaces 2017, 9, 11299-11306. [CrossRef] [PubMed]

35. Bernini, M.C.; García Blanco, A.A.; Villarroel-Rocha, J.; Fairen-Jimenez, D.; Sapag, K.; Ramirez-Pastor, A.J.; Narda, G.E. Tuning the target composition of amine-grafted CPO-27-Mg for capture of $\mathrm{CO}_{2}$ under post-combustion and air filtering conditions: A combined experimental and computational study. Dalton Trans. 2015, 44, 18970-18982. [CrossRef] [PubMed]

36. Pérez-Pellitero, J.; Amrouche, H.; Siperstein, F.R.; Pirngruber, G.; Nieto-Draghi, C.; Chaplais, G.; Simon-Masseron, A.; Bazer-Bachi, D.; Peralta, D.; Bats, N. Adsorption of $\mathrm{CO}_{2}, \mathrm{CH}_{4}$, and $\mathrm{N}_{2}$ on zeolitic imidazolate frameworks: Experiments and simulations. Chem. Eur. J. 2010, 16, 1560-1571. [CrossRef] [PubMed]

37. Danaci, D.; Singh, R.; Xiao, P.; Webley, P.A. Assessment of ZIF materials for $\mathrm{CO}_{2}$ capture from high pressure natural gas streams. Chem. Eng. J. 2015, 280, 486-493. [CrossRef]

38. Zhang, Z.; Xian, S.; Xi, H.; Wang, H.; Li, Z. Improvement of $\mathrm{CO}_{2}$ adsorption on ZIF-8 crystals modified by enhancing basicity of surface. Chem. Eng. Sci. 2011, 66, 4878-4888. [CrossRef]

39. Zhang, Z.; Xian, S.; Xia, Q.; Wang, H.; Li, Z.; Li, J. Enhancement of $\mathrm{CO}_{2}$ adsorption and $\mathrm{CO}_{2} / \mathrm{N}_{2}$ selectivity on ZIF-8 via postsynthetic modification. AIChE J. 2013, 59, 2195-2206. [CrossRef]

40. Martínez, F.; Sanz, R.; Orcajo, G.; Briones, D.; Yángüez, V. Amino-impregnated MOF materials for $\mathrm{CO}_{2}$ capture at post-combustion conditions. Chem. Eng. Sci. 2016, 142, 55-61. [CrossRef]

41. Cho, K.Y.; An, H.; Do, X.H.; Choi, K.; Yoon, H.G.; Jeong, H.-K.; Lee, J.S.; Baek, K.-Y. Synthesis of amine-functionalized ZIF-8 with 3-amino-1,2,4-triazole by postsynthetic modification for efficient $\mathrm{CO}_{2}$-selective adsorbents and beyond. J. Mater. Chem. A 2018, 6, 18912-18919. [CrossRef] 
42. Tsai, C.-W.; Niemantsverdriet, J.W.; Langner, E.H.G. Enhanced $\mathrm{CO}_{2}$ adsorption in nano-ZIF-8 modified by solvent assisted ligand exchange. Microporous Mesoporous Mater. 2018, 262, 98-105. [CrossRef]

43. Gadipelli, S.; Travis, W.; Zhou, W.; Guo, Z. A thermally derived and optimized structure from ZIF-8 with giant enhancement in $\mathrm{CO}_{2}$ uptake. Energy Environ. Sci. 2014, 7, 2232-2238. [CrossRef]

44. Ghahramaninezhad, M.; Soleimani, B.; Niknam Shahrak, M. A simple and novel protocol for Li-trapping with a POM/MOF nano-composite as a new adsorbent for $\mathrm{CO}_{2}$ uptake. New J. Chem. 2018, 42, 4639-4645. [CrossRef]

45. Mohamedali, M.; Ibrahim, H.; Henni, A. Incorporation of acetate-based ionic liquids into a zeolitic imidazolate framework (ZIF-8) as efficient sorbents for carbon dioxide capture. Chem. Eng. J. 2018, 334, 817-828. [CrossRef]

46. Wongsakulphasatch, S.; Kiatkittipong, W.; Saupsor, J.; Chaiwiseshphol, J.; Piroonlerkgul, P.; Parasuk, V.; Assabumrungrat, S. Effect of Fe open metal site in metal-organic frameworks on post-combustion $\mathrm{CO}_{2}$ capture performance. Greenhouse Gases Sci. Technol. 2017, 7, 383-394. [CrossRef]

47. Chen, Y.; Qiao, Z.; Huang, J.; Wu, H.; Xiao, J.; Xia, Q.; Xi, H.; Hu, J.; Zhou, J.; Li, Z. Unusual moisture-enhanced $\mathrm{CO}_{2}$ capture within microporous PCN-250 frameworks. ACS Appl. Mater. Interfaces 2020, 10, 38638-38647. [CrossRef]

48. Yang, Q.; Wiersum, A.D.; Jobic, H.; Guillerm, V.; Serre, C.; Llewellyn, P.L.; Maurin, G. Understanding the thermodynamic and kinetic behavior of the $\mathrm{CO}_{2} / \mathrm{CH}_{4}$ gas mixture within the porous zirconium terephthalate UiO-66(Zr): A joint experimental and modeling approach. J. Phys. Chem. C 2011, 115, 13768-13774. [CrossRef]

49. Cavka, J.H.; Grande, C.A.; Mondino, G.; Blom, R. High pressure adsorption of $\mathrm{CO}_{2}$ and $\mathrm{CH}_{4}$ on $\mathrm{Zr}-\mathrm{MOFs}$. Ind. Eng. Chem. Res. 2014, 53, 15500-15507. [CrossRef]

50. Andersen, A.; Divekar, S.; Dasgupta, S.; Cavka, J.H.; Aarti, A.; Nanoti, A.; Spjelkavik, A.; Goswami, A.N.; Garg, M.O.; Blom, R. On the development of Vacuum Swing adsorption (VSA) technology for post-combustion $\mathrm{CO}_{2}$ capture. Energy Procedia 2013, 37, 33-39. [CrossRef]

51. Kim, S.-N.; Lee, Y.-R.; Hong, S.-H.; Jang, M.-S.; Ahn, W.-S. Pilot-scale synthesis of a zirconium-benzenedicarboxylate $\mathrm{UiO}-66$ for $\mathrm{CO}_{2}$ adsorption and catalysis. Catal. Today 2015, 245, 54-60. [CrossRef]

52. Hon Lau, C.; Babarao, R.; Hill, M.R. A route to drastic increase of $\mathrm{CO}_{2}$ uptake in $\mathrm{Zr}$ metal organic framework UiO-66. Chem. Commun. 2013, 49, 3634-3636. [CrossRef]

53. Hong, D.H.; Suh, M.P. Enhancing $\mathrm{CO}_{2}$ separation ability of a metal-organic framework by post-synthetic ligand exchange with flexible aliphatic carboxylates. Chem. Eur. J. 2014, 20, 426-434. [CrossRef] [PubMed]

54. Li, L.J.; Liao, P.Q.; He, C.T.; Wei, Y.S.; Zhou, H.L.; Lin, J.M.; Li, X.Y.; Zhang, J.P. Grafting alkylamine in UiO-66 by charge-assisted coordination bonds for carbon dioxide capture from high-humidity flue gas. J. Mater. Chem. A 2015, 3, 21849-21855. [CrossRef]

55. Xian, S.; Wu, Y.; Wu, J.; Wang, X.; Xiao, J. Enhanced dynamic $\mathrm{CO}_{2}$ adsorption capacity and $\mathrm{CO}_{2} / \mathrm{CH}_{4}$ selectivity on polyethylenimine-impregnated UiO-66. Ind. Eng. Chem. Res. 2015, 54, 11151-11158. [CrossRef]

56. Mutyala, S.; Yu, Y.-D.; Jin, W.-G.; Wang, Z.-S.; Zheng, D.-Y.; Ye, C.-R.; Luo, B. $\mathrm{CO}_{2}$ capture using amine incorporated UiO-66 in atmospheric pressure. J. Porous Mater. 2019, 26, 1831-1838. [CrossRef]

57. Niu, Z.; Guan, Q.; Shi, Y.; Chen, Y.; Chen, Q.; Kong, Z.; Ning, P.; Tian, S.; Miao, R. A lithium-modified zirconium-based metal organic framework (UiO-66) for efficient $\mathrm{CO}_{2}$ adsorption. New J. Chem. 2018, 42, 19764-19770. [CrossRef]

58. Saha, B.B.; Jribi, S.; Koyama, S.; El-Sharkawy, I.I. Carbon dioxide adsorption isotherms on activated carbons. J. Chem. Eng. Data 2011, 56, 1974-1981. [CrossRef]

59. Lee, J.I.; Otto, F.D.; Mather, A.E. Equilibrium between carbon dioxide and aqueous monoethanolamine solutions. J. Appl. Chem. Biotechnol. 1976, 26, 541-549. [CrossRef]

60. Tsivadze, A.Y.; Aksyutin, O.E.; Ishkov, A.G.; Knyazeva, M.K.; Solovtsova, O.V.; Men'shchikov, I.E.; Fomkin, A.A.; Shkolin, A.V.; Khozina, E.V.; Grachev, V.A. Metal-organic framework structures: Adsorbents for natural gas storage. Russ. Chem. Rev. 2019, 88, 925-978. [CrossRef]

61. Sircar, S. Pressure Swing Adsorption. Ind. Eng. Chem. Res. 2002, 41, 1389-1392. [CrossRef]

62. Chou, C.-T.; Chen, C.-Y. Carbon dioxide recovery by vacuum swing adsorption. Sep. Purif. Technol. 2004, 39, 51-65. [CrossRef] 
63. Tranchemontagne, D.J.; Hunt, J.R.; Yaghi, O.M. Room temperature synthesis of metal-organic frameworks: MOF-5, MOF-74, MOF-177, MOF-199, and IRMOF-0. Tetrahedron 2008, 64, 8553-8557. [CrossRef]

64. Musto, P.; La Manna, P.; Pannico, M.; Mensitieri, G.; Gargiulo, N.; Caputo, D. Molecular interactions of $\mathrm{CO}_{2}$ with the CuBTC metal organic framework: An FTIR study based on two-dimensional correlation spectroscopy. J. Mol. Struct. 2018, 1166, 326-333. [CrossRef]

65. Da Silva, F.; Magalhães, G.; Jardim, E.; Silvestre-Albero, J.; Sepúlveda-Escribano, A.; De Azevedo, D.; De Lucena, S. $\mathrm{CO}_{2}$ adsorption on ionic liquid-modified Cu-BTC: Experimental and simulation study. Adsorpt. Sci. Technol. 2015, 33, 223-242. [CrossRef]

66. Prestipino, C.; Regli, L.; Vitillo, J.G.; Bonino, F.; Damin, A.; Lamberti, C.; Zecchina, A.; Solari, P.L.; Kongshaug, K.O.; Bordiga, S. Local Structure of Framework Cu(II) in HKUST-1 Metallorganic Framework: spectroscopic characterization upon activation and interaction with Adsorbates. Chem. Mater. 2006, 18, 1337-1346. [CrossRef]

67. Low, J.J.; Benin, A.I.; Jakubczak, P.; Abrahamian, J.F.; Faheem, S.A.; Willis, R.R. Virtual high throughput screening confirmed experimentally: Porous coordination polymer hydration. J. Am. Chem. Soc. 2009, 131, 15834-15842. [CrossRef] [PubMed]

68. Al-Janabi, N.; Hill, P.; Torrente-Murciano, L.; Garforth, A.; Gorgojo, P.; Siperstein, F.; Fan, X. Mapping the $\mathrm{Cu}-\mathrm{BTC}$ metal-organic framework (HKUST-1) stability envelope in the presence of water vapour for $\mathrm{CO}_{2}$ adsorption from flue gases. Chem. Eng. J. 2015, 281, 669-677. [CrossRef]

69. Grajciar, L.; Nachtigall, P.; Bludsky, O.; Rubes, M. Accurate Ab initio description of adsorption on Coordinatively unsaturated $\mathrm{Cu}^{2+}$ and $\mathrm{Fe}^{3+}$ sites in MOFs. J. Chem. Theor. Comput. 2015, 11, 230-238. [CrossRef]

70. Qasem, N.A.A.; Ben-Mansour, R. Adsorption breakthrough and cycling stability of carbon dioxide separation from $\mathrm{CO}_{2} / \mathrm{N}_{2} / \mathrm{H}_{2} \mathrm{O}$ mixture under ambient conditions using 13X and Mg-MOF-74. Appl. Energy 2018, 230, 1093-1107. [CrossRef]

71. Mangano, E.; Kahr, J.; Wright, P.A.; Brandani, S. Accelerated degradation of MOFs under flue gas conditions. Faraday Discuss. 2016, 192, 181-195. [CrossRef]

72. McEwen, J.; Hayman, J.-D.; Ozgur Yazaydin, A. A comparative study of $\mathrm{CO}_{2}, \mathrm{CH}_{4}$ and $\mathrm{N}_{2}$ adsorption in ZIF-8, Zeolite-13X and BPL activated carbon. Chem. Phys. 2013, 412, 72-76. [CrossRef]

73. Sayari, A.; Belmabkhout, Y. Stabilization of amine-containing $\mathrm{CO}_{2}$ adsorbents: Dramatic effect of water vapor. J. Am. Chem. Soc. 2010, 132, 6312-6314. [CrossRef] [PubMed]

74. Zeeshan, M.; Keskin, S.; Uzun, A. Enhancing $\mathrm{CO}_{2} / \mathrm{CH}_{4}$ and $\mathrm{CO}_{2} / \mathrm{N}_{2}$ separation performances of ZIF-8 by postsynthesis modification with [BMIM][SCN]. Polyhedron 2018, 155, 485-492. [CrossRef]

75. Ferreira, T.J.; Ribeiro, R.P.P.L.; Mota, J.P.B.; Rebelo, L.P.N.; Esperança, J.M.S.S.; Esteves, I.A.A.C. Ionic liquid-impregnated metal-organic frameworks for $\mathrm{CO}_{2} / \mathrm{CH}_{4}$ separation. ACS Appl. Nano Mater. 2019, 2, 7933-7950. [CrossRef]

76. Idris, I.; Abdullah, A.; Shamsudin, I.K.; Othman, M.R. Comparative analyses of carbon dioxide capture from power plant flue gas surrogate by micro and mesoporous adsorbents. J. Environ. Chem. Eng. 2019, 7, 103115. [CrossRef]

77. Hu, Z.; Sun, Y.; Zeng, K.; Zhao, D. Structural-failure resistance of metal-organic frameworks toward multiple-cycle $\mathrm{CO}_{2}$ sorption. Chem. Commun. 2017, 53, 8653-8656. [CrossRef]

78. Edubilli, S.; Gumma, S. A systematic evaluation of UiO-66 metal organic framework for $\mathrm{CO}_{2} / \mathrm{N}_{2}$ separation. Sep. Purif. Technol. 2019, 224, 85-94. [CrossRef]

79. Abdullah, A.; Idris, I.; Shamsudin, I.K.; Othman, M.R. Methane enrichment from high carbon dioxide content natural gas by pressure swing adsorption. J. Nat. Gas Sci. Eng. 2019, 69, 102929. [CrossRef]

80. MOF Manufacturing. Available online: https://www.moftechnologies.com/manufacturing/ (accessed on 5 March 2020).

81. Chanut, N.; Wiersum, A.D.; Lee, U.-H.; Hwang, Y.K.; Ragon, F.; Chevreau, H.; Bourrelly, S.; Kuchta, B.; Chang, J.-S.; Serre, C.; et al. Observing the effects of shaping on gas adsorption in metal-organic frameworks. Eur. J. Inorg. Chem. 2016, 2016, 4416-4423. [CrossRef]

82. Zheng, J.; Cui, X.; Yang, Q.; Ren, Q.; Yang, Y.; Xing, H. Shaping of ultrahigh-loading MOF pellet with a strongly anti-tearing binder for gas separation and storage. Chem. Eng. J. 2018, 354, 1075-1082. [CrossRef] 
83. Mallick, A.; Mouchaham, G.; Bhatt, P.M.; Liang, W.; Belmabkhout, Y.; Adil, K.; Jamal, A.; Eddaoudi, M. Advances in Shaping of Metal-Organic Frameworks for $\mathrm{CO}_{2}$ Capture: Understanding the Effect of Rubbery and Glassy Polymeric Binders. Ind. Eng. Chem. Res. 2018, 57, 16897-16902. [CrossRef]

84. Ribeiro, R.P.P.L.; Antunes, C.L.; Garate, A.U.; Portela, A.F.; Plaza, M.G.; Mota, J.P.B.; Esteves, I.A.A.C. Binderless shaped metal-organic framework particles: Impact on carbon dioxide adsorption. Microporous Mesoporous Mater. 2019, 275, 111-121. [CrossRef]

85. Valizadeh, B.; Nguyen, T.N.; Stylianou, K.C. Shape engineering of metal-organic frameworks. Polyhedron 2018, 145, 1-15. [CrossRef]

86. Danaci, D.; Bui, M.; Mac Dowell, N.; Petit, C. Exploring the limits of adsorption-based $\mathrm{CO}_{2}$ capture using MOFs with PVSA-From molecular design to process economics. Mol. Syst. Des. Eng. 2020, 5, 212-231. [CrossRef]

87. World Energy Outlook 2016-Analysis_IEA. Available online: https://www.iea.org/reports/world-energyoutlook-2016 (accessed on 26 March 2020).

88. Fioletov, V.E.; McLinden, C.A.; Krotkov, N.; Li, C.; Joiner, J.; Theys, N.; Carn, S.; Moran, M.D. A global catalogue of large $\mathrm{SO}_{2}$ sources and emissions derived from the Ozone Monitoring Instrument. Atmos. Chem. Phys. 2016, 16, 11497-11519. [CrossRef]

89. Britt, D.; Tranchemontagne, D.; Yaghi, O.M. Metal-organic frameworks with high capacity and selectivity for harmful gases. Proc. Natl. Acad. Sci. USA 2008, 105, 11623-11627. [CrossRef]

90. Bobbitt, N.S.; Mendonca, M.L.; Howarth, A.J.; Islamoglu, T.; Hupp, J.T.; Farha, O.K.; Snurr, R.Q. Metal-organic frameworks for the removal of toxic industrial chemicals and chemical warfare agents. Chem. Soc. Rev. 2017, 46, 3357-3385. [CrossRef]

91. Wang, H.; Lustig, W.P.; Li, J. Sensing and capture of toxic and hazardous gases and vapors by metal-organic frameworks. Chem. Soc. Rev. 2018, 47, 4729-4756. [CrossRef]

92. Han, X.; Yang, S.; Schröder, M. Porous metal-organic frameworks as emerging sorbents for clean air. Nat. Rev. Chem. 2019, 3, 108-118. [CrossRef]

93. Glomb, S.; Woschko, D.; Makhloufi, G.; Janiak, C. Metal-organic frameworks with internal urea-functionalized dicarboxylate linkers for $\mathrm{SO}_{2}$ and $\mathrm{NH}_{3}$ adsorption. ACS Appl. Mater. Interfaces 2017, 9, 37419-37434. [CrossRef]

94. Dathe, H.; Peringer, E.; Roberts, V.; Jentys, A.; Lercher, J.A. Metal organic frameworks based on $\mathrm{Cu}^{2+}$ and benzene-1,3,5-tricarboxylate as host for $\mathrm{SO}_{2}$ trapping agents. Comptes Rendus Chim. 2005, 8, 753-763. [CrossRef]

95. Brandt, P.; Nuhnen, A.; Lange, M.; Möllmer, J.; Weingart, O.; Janiak, C. Metal-organic frameworks with potential application for $\mathrm{SO}_{2}$ separation and flue gas desulfurization. ACS Appl. Mater. Interfaces 2019, 11, 17350-17358. [CrossRef] [PubMed]

96. Ebrahim, A.M.; Levasseur, B.; Bandosz, T.J. Interactions of $\mathrm{NO}_{2}$ with $\mathrm{Zr}$-based MOF: Effects of the size of organic linkers on $\mathrm{NO}_{2}$ adsorption at ambient conditions. Langmuir 2013, 29, 168-174. [CrossRef] [PubMed]

97. Tancrede, M.; Wilson, R.; Zeise, L.; Crouch, E.A.C. The carcinogenic risk of some organic vapors indoors: A theoretical survey. Atmos. Environ. 1987, 19, 2187-2205. [CrossRef]

98. Molhave, L. Indoor climate, air pollution, and human comfort. J. Expo. Sci. Environ. Epidemiol. 1991, 1, 63-81.

99. Zheng, C.; Shen, J.; Zhang, Y.; Huang, W.; Zhu, X.; Wu, X.; Chen, L.; Gao, X.; Cen, K. Quantitative assessment of industrial VOC emissions in China: Historical trend, spatial distribution, uncertainties, and projection. Atmos. Environ. 2017, 150, 116-125. [CrossRef]

100. Yang, K.; Xue, F.; Sun, Q.; Yue, R.; Lin, D. Adsorption of volatile organic compounds by metal-organic frameworks MOF-177. J. Environ. Chem. Eng. 2013, 1, 713-718. [CrossRef]

101. Zhou, L.; Zhang, X.; Chen, Y. Facile synthesis of Al-fumarate metal-organic framework nano-flakes and their highly selective adsorption of volatile organic compounds. Mater. Lett. 2017, 197, 224-227. [CrossRef]

102. Zhang, X.; Yang, Y.; Song, L.; Chen, J.; Yang, Y.; Wang, Y. Enhanced adsorption performance of gaseous toluene on defective UiO-66 metal organic framework: Equilibrium and kinetic studies. J. Hazard. Mater. 2019, 365, 597-605. [CrossRef]

103. Saha, D.; Deng, S. Structural Stability of Metal Organic Framework MOF-177. J. Phys. Chem. Lett. 2010, 1, 73-78. [CrossRef] 
104. Vellingiri, K.; Szulejko, J.E.; Kumar, P.; Kwon, E.E.; Kim, K.-H.; Deep, A.; Boukhvalov, D.W.; Brown, R.J.C. Metal organic frameworks as sorption media for volatile and semi-volatile organic compounds at ambient conditions. Sci. Rep. 2016, 6, 27813. [CrossRef]

105. Uzoigwe, C.E.; Sanchez Franco, L.C.; Forrest, M.D. Iatrogenic greenhouse gases: The role of anaesthetic agents. Br. J. Hosp. Med. 2016, 77, 19-23. [CrossRef] [PubMed]

106. Ishizawa, Y. General anesthetic gases and the global environment. Anesth. Analg. 2011, 112, $213-217$. [CrossRef]

107. Anesthetic Gases: Guidelines for Workplace Exposures|Occupational Safety and Health Administration. Available online: https://www.osha.gov/dts/osta/anestheticgases/ (accessed on 1 April 2020).

108. Gargiulo, N.; Peluso, A.; Aprea, P.; Eić, M.; Caputo, D. An insight into clustering of halogenated anesthetics molecules in metal-organic frameworks: Evidence of adsorbate self-association in micropores. J. Colloid Interface Sci. 2019, 554, 463-467. [CrossRef] [PubMed]

109. Gargiulo, N.; Peluso, A.; Aprea, P.; Hua, Y.; Filipović, D.; Caputo, D.; Eić, M. A chromium-based metal organic framework as a potential high performance adsorbent for anaesthetic vapours. RSC Adv. 2014, 4, 49478-49484. [CrossRef]

110. Hua, Y.; Gargiulo, N.; Peluso, A.; Aprea, P.; Eić, M.; Caputo, D. Adsorption Behavior of Halogenated Anesthetic and Water Vapor on Cr-Based MOF (MIL-101) Adsorbent. Part I. Equilibrium and Breakthrough Characterizations. Chem. Ing. Tech. 2016, 88, 1730-1738. [CrossRef]

111. Hua, Y.; Gargiulo, N.; Peluso, A.; Aprea, P.; Eić, M.; Caputo, D. Adsorption Behavior of Halogenated Anesthetic and Water Vapor on Cr-Based MOF (MIL-101) Adsorbent. Part II. Multiple-Cycle Breakthrough Tests. Chem. Ing. Tech. 2016, 88, 1739-1745. [CrossRef]

112. Bloch, E.D.; Queen, W.L.; Krishna, R.; Zadrozny, J.M.; Brown, C.M.; Long, J.R. Hydrocarbon Separations in a Metal-Organic Framework with Open Iron(II) Coordination Sites. Science 2012, 335, 1606-1610. [CrossRef]

113. McDonald, T.M.; Mason, J.A.; Kong, X.; Bloch, E.D.; Gygi, D.; Dani, A.; Crocellà, V.; Giordanino, F.; Odoh, S.O.; Drisdell, W.S.; et al. Cooperative insertion of $\mathrm{CO}_{2}$ in diamine-appended metal-organic frameworks. Nature 2015, 519, 303-308. [CrossRef]

114. Losch, P.; Huang, W.; Goodman, E.D.; Wrasman, C.J.; Holm, A.; Riscoe, A.R.; Schwalbe, J.A.; Cargnello, M. Colloidal nanocrystals for heterogeneous catalysis. Nano Today 2019, 24, 15-47. [CrossRef]

115. Riscoe, A.R.; Wrasman, C.J.; Herzing, A.A.; Hoffman, A.S.; Menon, A.; Boubnov, A.; Vargas, M.; Bare, S.R.; Cargnello, M. Transition state and product diffusion control by polymer-nanocrystal hybrid catalysts. Nat. Catal. 2019, 2, 852-863. [CrossRef] 